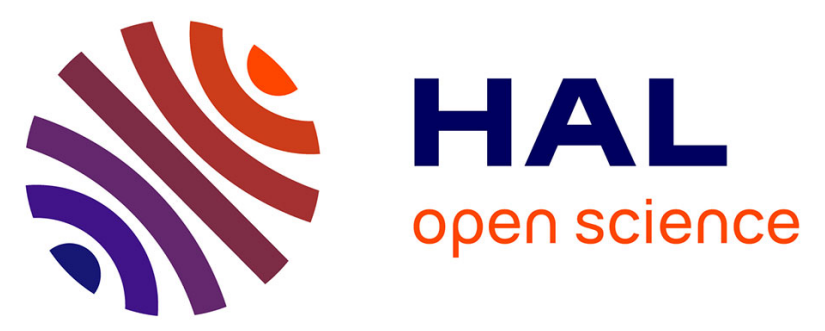

\title{
Quantifying preferences around vaccination against frequent, mild disease with risk for vulnerable persons: A discrete choice experiment among French hospital health care workers
}

Léo Donzel Godinot, Jonathan Sicsic, Marie Lachâtre, Dominique Abiteboul, Elisabeth Rouveix, Gérard Pélissier, Jocelyn Raude, Judith E. Mueller

\section{To cite this version:}

Léo Donzel Godinot, Jonathan Sicsic, Marie Lachâtre, Dominique Abiteboul, Elisabeth Rouveix, et al.. Quantifying preferences around vaccination against frequent, mild disease with risk for vulnerable persons: A discrete choice experiment among French hospital health care workers. 2020. halshs03008549

\section{HAL Id: halshs-03008549 \\ https://shs.hal.science/halshs-03008549}

Preprint submitted on 16 Nov 2020

HAL is a multi-disciplinary open access archive for the deposit and dissemination of scientific research documents, whether they are published or not. The documents may come from teaching and research institutions in France or abroad, or from public or private research centers.
L'archive ouverte pluridisciplinaire HAL, est destinée au dépôt et à la diffusion de documents scientifiques de niveau recherche, publiés ou non, émanant des établissements d'enseignement et de recherche français ou étrangers, des laboratoires publics ou privés. 


\section{Quantifying preferences around vaccination against frequent, mild disease} with risk for vulnerable persons: A discrete choice experiment among French hospital health care workers

Léo Donzel Godinot (1)

Jonathan Sicsic*(2)

Marie Lachatre $(3,4)$

Elisabeth Bouvet (5)

Dominique Abiteboul (3)

Elisabeth Rouveix (5)

Gerard Pelissier (3)

Jocelyn Raude $(1,6)$

Judith E. Mueller $(1,7)$

(1) EHESP French School of Public Health, Paris and Rennes, France at the time of writting. Current: CHU de Bordeaux

(2) Université de Paris, LIRAES (EA 4470), Paris, France

(3) Research Group for the Prevention of Occupational Infections in Healthcare Workers (GERES), Paris, France

(4) CIC Cochin-Pasteur 1417, Hôpital Cochin/APHP, Paris, France

(5) Haute autorité de santé (HAS), Commission technique des vaccinations (CTV), La Plaine Saint Denis, France

(6) Unité des Virus Émergents (UVE: Aix-Marseille Univ - IRD 190 - Inserm 1207 - IHU Méditerranée Infection), Marseille, France

(7) Institut Pasteur, Paris, France

* Corresponding author: Jonathan Sicsic

Université de Paris, LIRAES (EA 4470), 45 rue des Saints-Pères, 75006 Paris, France Jonathan.sicsic@u-paris.fr 
Working Paper. Preferences around vaccination among French health care workers

Keywords: France; Vaccination; Influenza; Pertussis; Health care workers; Stated preferences discrete choice experiment; Incentives; Social conformism

\section{Abstract}

The individual determinants of vaccine acceptance among health workers (HCWs) have been described in the literature, but there is little evidence regarding the impact of vaccine characteristics and contextual factors (e.g., incentives, communication) on vaccination intentions. We developed a discrete choice experiment (DCE) to assess the impact of seven attributes on stated vaccination intention against an unnamed disease, described as frequent with rapid clinical evolution and epidemic potential (similar to influenza or pertussis). Attributes evaluated vaccine characteristics (effectiveness, security profile), inter-individual aspects (epidemic risk, controversy, potential for indirect protection, vaccine coverage) and incentives (e.g., badge, hierarchical injunction). A total of 1214 French hospital-based HCWs, recruited among professional organizations, completed the online DCE questionnaire. The relative impact of each attribute was estimated using random effects logit models on the whole sample and among specific subgroups. Overall, $52 \%$ of included HCWs were vaccinated against influenza during 2017-18 and the average vaccination acceptance rate across all scenarios was 58\%. Except for attitude from the management, all attributes' levels had significant impact on vaccination decisions. Poor vaccine safety had the most detrimental impact on stated acceptance (OR 0.04 for the level controversy around vaccine safety). The most motivating factor was protection of family (OR 2.41) and contribution to disease control (OR 2.34). Other motivating factors were improved vaccine effectiveness (OR 2.22), high uptake among colleagues (OR 1.89) and epidemic risk declared by health authorities (OR 1.76). Social incentives (e.g., a badge I'm vaccinated) were dissuasive (OR 0.47). Compared to HCWs previously vaccinated against influenza, unvaccinated HCWs who were favorable to vaccination in general were most sensitive towards improved vaccine effectiveness. Our study suggests that vaccine safety considerations 
Working Paper. Preferences around vaccination among French health care workers

dominate vaccine decision-making among French HCWs, while adapted communication on indirect protection and social conformism can contribute to increase vaccination acceptance.

\section{Introduction}

Low uptake of recommended vaccinations is a worldwide problem for public health. Low acceptance or hesitancy by the target population or specific subgroups has been identified a main factor for vaccine refusal (MacDonald and SAGE Working Group on Vaccine Hesitancy, 2015). A substantial body of literature has described the determinants of acceptance (and refusal) of specific vaccinations, including that of health care workers, thus informing on the characteristics of persons accepting vaccination. However, individuals' positions towards vaccination is now understood as a continuum of vaccination hesitancy, ranging from full refusal to full acceptation, on which individuals can move depending on the type of disease to be prevented, type of vaccine, and several other factors, commonly structured into convenience, complacency and confidence (MacDonald and SAGE Working Group on Vaccine Hesitancy, 2015).

Understanding the features of vaccination programs that allow hesitant individuals to move from refusal towards acceptance in specific vaccine decisions are therefore of utmost importance. So far, few research efforts have focused on this aspect. The perspective in this approach is to move from descriptive towards interventional research, to improve communication, strategies and other elements of vaccination programs.

Because there is little variation in public health programs (e.g., vaccination) within populations, it is difficult to infer the drivers of individual decisions using observed choices (i.e., revealed preferences). Discrete choice experiments (DCEs) have been developed to overcome this limitation (Ryan, 1999). DCEs allow exploring the determinants of individual preferences for different health intervention (e.g., a treatment, a preventative or screening program) in hypothetical settings. The service or intervention in question is described by different characteristics or attributes. The attributes are arranged into multi-attribute alternative options 
Working Paper. Preferences around vaccination among French health care workers (e.g., treatments), which are presented in choice sets of two or more options. The DCE task requires individuals to choose their preferred option. Econometric analysis of responses then allows quantifying the weights individuals attach to various attributes of the health intervention in order to finally predict their independent impact on decisions. DCEs have increasingly been used for valuing treatments, preventative or screening interventions (Bridges et al., 2011; Clark et al., 2014; Johnson et al., 2014; Ryan and Gerard, 2003). More recently, this approach has also been used to elicit preferences not only for vaccines, but vaccination programs, including programmatic and interindividual factors as attributes (Determann et al., 2016; Seanehia et al., 2017; Verelst et al., 2018). Seanehia et al. (2017) conducted a DCE study among French students and concluded that an explicitly stated potential for indirect protection, and factual information on coverage in the community positively impact theoretical individual vaccine acceptance, while a controversy about potential side effects may have greater negative impact than a confirmed rare severe side effect. Another DCE study among Belgian parents showed that vaccine-related side effects and accessibility (in terms of convenience and reimbursement) were the most influential attributes, followed by vaccine effectiveness and burden of disease (Verelst et al., 2018). Besides, peer influence had a greater influence on vaccine decision than free-riding on herd immunity (Verelst et al., 2018).

Seasonal influenza is recommended for health care workers (HCWs) in most European countries (Maltezou and Poland, 2014; Mereckiene et al., 2014), to reduce work days lost and to interrupt the viral transmission to vulnerable patients (Hayward et al., 2006). However, influenza vaccine coverage among HCWs in Europe remains in general below 40\% (Jorgensen et al., 2018). In France, seasonal influenza vaccination among HCWs was estimated at $25.6 \%$ in 200809 (55.0\%, 24.4\% and 19.5\% among physicians, nurses and nurse assistants, respectively) (Guthmann et al., 2012), but recent estimates suggest an increasing trend in coverage, with 
$34.8 \%$ of HCWs vaccinated in 2018-19 (72,2\%, 35,9\% and 20,9\% among physicians, nurses and nurse assistants, respectively) (Santé Publique France, 2019) Mandatory vaccination has been

suggested as a solution, following the example of the US hospitals and health care organizations (Greene et al., 2018). A similar situation exists for pertussis (whooping cough) vaccination, which is recommended for HCWs in contact with new-born babies to avoid nosocomial infection (Calugar et al., 2006), but for which coverage remains below the target in France (45\% among midwifes, $11 \%$ among HCWs in general) (Guthmann et al., 2012).

The reasons for vaccination refusal by HCWs have been described as misconceptions about the disease (e.g., influenza) and its vaccine (Boey et al., 2018), the perception of low or inconstant vaccine effectiveness, decisional uncertainty (Visser et al., 2018), vaccine safety and fear of adverse events following vaccination (Dorribo et al., 2015), and the belief that the risk of disease transmission during care activities is low or can be avoided by hygienic measures (Doumont and Libion, 2007; Gil et al., 2006). On the other hand, protection for oneself, the family or patients has been identified as reason for acceptance (Hakim et al., 2011; Valour et al., 2007). However, the relative importance of these factors, and the extent to which motivating factors can compensate for low disease risk and worry about the vaccine safety profile, has not been studied, yet. Moreover, the impact of external incentives on vaccination acceptance has not been evaluated in this context.

In the present study, we aimed at evaluating preferences for vaccination program characteristics - beyond vaccine access - among French HCWs practicing in hospitals. In particular, we sought to evaluate communication options around specific program aspects (e.g., coverage, safety, potential for indirect protection) and the effect of incentives. The hypotheses underlying this study were mainly structured according to the health belief model in vaccination (Paulussen et al., 2006; Rosenstock, 1974), proposing the perceived likelihood and severity of disease, the perceived benefits, risks and costs of vaccination as determinants of vaccine 
Working Paper. Preferences around vaccination among French health care workers

acceptance. We assumed that disease risk perception and vaccine-related factors (safety and effectiveness) would have the strongest impacts on HCWs' vaccination decisions, but that inter-

individual level factors (social conformism, potential for indirect protection) and communication modalities (incentives, injunction) can offset these effects to a substantial extent. We also hypothesized that these impacts may vary across groups defined by health-related behavior, attitudes towards vaccination and towards health authorities.

\section{Methods}

\subsection{Study design and participant inclusion}

We conducted a cross-sectional study among French HCWs using a self-administered online questionnaire containing a single profile discrete choice experiment (DCE). The study invitation was addressed to any HCW practicing in France, including students and HCWs in French oversea departments. Respondents indicating that they worked independently, i.e., outside the hospital, a nursing home or a comparable institution, received a different version of the questionnaire and were excluded from the present analysis. The invitation was distributed by e-mail to a professional registry $(18,120$ entries) and to two professional organizations: the Research Group for the Prevention of Occupational Infections in Healthcare Workers (GERES) and the National College of Nurses (approximately 300,000 members in total), without any reminder message. Due to the 'snowball' sampling technique (investigators recruited HCWs from their acquaintances) used by one professional organization (the GERES) to reach HCW outside the organization, the number of $\mathrm{HCW}$ having received the invitation - and thus the response rate and representativeness - could not be estimated. The National College of Nurses included the invitation inside their monthly newsletter, which was sent to 230,000 French nurses and nursing managers. The e-mail contained some basic information about the study's objectives 
and methods, the anticipated time required for participation (i.e., 15-20 minutes) and a link to the anonymous questionnaire on the Sphinx ${ }^{\circledR}$ online survey platform. No informed consent was

required for this anonymous survey. We obtained approval from a French ethics committee (CPP Sud-Est V). The survey platform was open during June 18 through September 06, 2018.

The questionnaire contained three parts. The first part asked general background information (e.g., profession and socio-demographic characteristics). The second part contained the DCE tool. The third part collected information on vaccine behaviors and attitudes, including sources of vaccine information, vaccine hesitancy on a four levels scale (Verger, 2017) and health-related behavior (e.g., use of alternative medicine, smoking).

\subsection{Design of the DCE tool}

\section{Attributes and levels}

The attributes and levels included in the DCE were identified following a review of the literature on determinants of acceptance and refusal of vaccination among HCWs (Boey et al., 2018; Dorribo et al., 2015; Hakim et al., 2011; Visser et al., 2018), with a focus on influenza and pertussis vaccination, and through discussion between eight experts and stakeholders (social scientist, epidemiologist, professional organizations, and occupational health). Given an abundant (grey) literature including from France, we refrained from additional qualitative work to identify attributes and levels. We established a list of possible attributes and levels and eliminated items stepwise in discussion between co-authors, until consensus on the most important items was reached. We considered essential to include items corresponding to the above-mentioned health belief model, as well as the 3C-concept of vaccine hesitancy (convenience, complacency and confidence) (McDonald et al., 2015), along with social 
Working Paper. Preferences around vaccination among French health care workers

conformism and indirect protection (Seanehia et al., 2017). Convenience was fixed in the frame, defined as the hypothetical situation of a meeting organized by the occupational health service, with the objective to provide information about the vaccine and to offer immediate free

vaccination. The targeted vaccine-preventable disease was not named but described according to characteristics of influenza and whooping cough: high incidence and seasonal patterns, easily transmitted during close contacts, with a low risk of complications, except for specific vulnerable groups (infants, elderly, chronic disease patients). A total of seven attributes were included in the hypothetical vaccination scenarios (Table 1).

- The attribute EPI (4 levels) referred to the epidemic situation and was designed to test how disease risk perception influenced vaccination acceptance. We assumed that the level "cases among colleagues" would have the highest positive impact on vaccine acceptance. Indeed, disease risk perception is a main reason for vaccination (Setbon and Raude, 2010), and colleagues are the most reliable information and also the most immediate threat.

- The SAFETY attribute (4 levels) described various situations of vaccine-related side effects. It was developed to test whether a public controversy or a recent vaccine with uncertain safety profile impacted vaccine acceptance as negatively as a confirmed severe side effect, as already observed among French students (Seanehia et al., 2017).

- The attribute EFFECTIVENESS (4 levels) evaluated whether an improved vaccine (90\% vaccine effectiveness instead of the regularly observed 30\% against influenza (Bonmarin et al., 2015)), and larger intervals (every 3-5 years instead of annual vaccination) could stimulate vaccine acceptance.

- The COVERAGE attribute (5 levels) was designed to test the impact of social conformism and free-riding on vaccination acceptance, and whether social conformism was stronger towards colleagues or the general HCW population (Hastings et al., 2004). 


\section{Working Paper. Preferences around vaccination among French health care workers}

The reference level "insufficient coverage" represented a commonly used communication formula, which we hypothesized to have no positive impact on vaccine acceptance,

contrary to factual communication of low coverage (30\%) or occasional uptake ("a few colleagues").

- The attribute INDIRECT PROTECTION (4 levels) was designed to assess the extent to which communication on supra-individual benefits from vaccination can improve vaccine acceptance (Shim et al., 2012). Indirect protection conferred by a vaccine leads to the effect of herd protection in the population, meaning that the average disease risk is reduced due to reduced pathogen transmission. The risk reduction or the disease control becomes more important as vaccine coverage increases and eventually can reach the level of herd immunity, at which the pathogen does not circulate and thus the disease is eliminated from the population (Fine et al., 2011). We hypothesized that reference to a collective goal (disease control) not involving personal altruism (protection of family, patients) had the highest positive impact, in line with previous results among French university students (Seanehia et al., 2017).

- The attribute INCENTIVES (4 levels) tested whether announced incentives or punishment had any positive impact on vaccine acceptance (Lugo, 2007). We had no a priori assumption, because the effect may depend on the complementarity / substitutability between intrinsic motivation (or altruistic motives) towards vaccination and external incentives (Frey, 1994; Janus, 2010).

- The MANAGEMENT attribute (2 levels) tested whether a pro-vaccine message of the hospital management team (chief officer), representing a hierarchical injunction with a health-related utility (avoiding work days lost), had positive impact on vaccine acceptance (Canning et al., 2005; Lugo, 2007). 
We performed a pilot study by having six health professionals in our environment (one nurse, two physicians, two medical students and one pharmacist) self-administering the questionnaire and providing feedback that helped us simplify the introduction text of every scenario, and clarify the formulation of some levels.

\section{Experimental design}

This list of attributes would theoretically allow constructing 10,240 hypothetical vaccination profiles (i.e., scenarios with only one vignette) in a full factorial design. We used SAS® software to generate a 32-profile orthogonal design with non-informative priors and allowing estimation of all main effects. We constrained the final design to incorporate two specific attributes' combinations corresponding to contexts that aimed to closely mimic 1) the influenza vaccination situation and 2) the pertussis vaccination situation (see Figures A1 and A2, supplementary file A). Moreover, several constraints were added to avoid implausible combinations of attributes. These constraints automatically generated some correlations between attributes, but these correlations were low as the final design was $90.5 \%$ D-efficient compared to the best possible orthogonal design (see Table A1 for detailed model constraints). This initial choice set was 'blocked' into two versions of the survey each with 16 profiles (the 'blocking' procedure allowing minimizing the correlation between the attributes in each version) (Reed Johnson et al., 2013).

In each choice task, we presented one hypothetical vaccination profile to participants and asked whether or not they would accept immediate vaccination (single profile DCE format, see Figure 1 for an example choice task). In the vaccination context, individuals are used to make binary choices such as to vaccine or not to vaccine, rather than choosing between several alternative vaccines. We hypothesized that a single profile choice design would increase the 


\section{Working Paper. Preferences around vaccination among French health care workers}

realism of the choice task and thus survey engagement, such that any potential loss in statistical efficiency (only one profile per choice task) would be compensated by an increase in data quality.

If vaccination was accepted, willingness to accept pain associated with vaccination was evaluated by asking for which maximum level of pain the respondent was willing to be vaccinated (Figure 1). Four ordinal levels were presented to respondents: minor pain during the injection; redness / swelling at the injection site for one day; minor arm pain during three days; one day with fever while you need to stay in bed. We included a briefing on how to complete the choice tasks before the beginning of the DCE (see supplementary file $\mathbf{B}$ ).

\subsection{Statistical analyses}

We estimated the determinants of vaccination acceptance using a random intercept logit model, detailed in Eq. (1):

$$
\begin{gathered}
\operatorname{logit}\left[\text { P }\left(\text { Accept }_{n j}\right)\right]=\beta_{0}+\beta_{1-3} \text { EPI }_{n j}+\beta_{4-6} \text { SAFETY }_{n j}+\beta_{7-9} \text { EFFECTIVENESS }_{n j} \\
+\beta_{10-13} \text { COVERAGE }_{n j}+\beta_{14-16} \text { INDIRECT PROTECTION }_{n j}+\beta_{17-19} \text { INCENTIVE }_{n j} \\
+\beta_{20} \text { MANAGEMENT }_{n j}+u_{n}
\end{gathered}
$$

In Eq. (1), Accept $_{n j}$ is a binary indicator coded 1 if respondent $n$ accepts the hypothetical vaccination profile $\mathrm{j} ; E P I_{n j}, \ldots, M_{A N A G E M E N T_{n j}}$ represent the levels of the attributes displayed in scenario $\mathrm{j} ; \beta_{x-y}$ is a vector of corresponding part-worth utility coefficients for all levels $x$ - $y$ of attribute $\mathrm{k}$; and $u_{n}$ is a subject-specific random error term, assumed normally distributed and representing respondent' $\mathrm{n}$ propensity to accept / not accept the hypothetical vaccines. Note that the logit specification in equation (1) further assumes that all other unobserved factors and idiosyncrasies influencing $\mathrm{P}\left(\right.$ Accept $\left._{\mathrm{nj}}\right)$ follow a type 1 extreme value distribution. Because all respondents (in a same survey block) faced the same vaccination profiles or scenarios (and thus were exposed to the same attributes' levels combinations), the 
Working Paper. Preferences around vaccination among French health care workers

explanatory variables were exogenous such that fixed effects and random effects estimators for panel data collapse (Wooldridge, 2002, chapter 10). The random intercept model was estimated by Gauss-Hermite quadrature.

We computed the overall significance of the attributes using likelihood ratio tests - that is, by considering the difference in models log likelihoods for an attribute (with all its levels) in and out of a model (Lancsar et al., 2007) - and measured the relative importance of the attributes by the $\log$ worth statistic, i.e. $-\log _{10}\left(\chi_{2}\right.$ of the LR test).

We explored the impact of individual characteristics on preference weights (observed preference heterogeneity) in several steps. First, we re-estimated Eq. (1) by adding interactions between all attributes' levels and individual characteristics including background information (e.g., gender, age, profession), attitudes towards vaccination, and vaccine information from media and health authorities (in total: 26 attribute levels $*$ nine personal characteristics $=234$ interactions tested). Next, we included only the significant interaction effects (at the 5\% level) in a joint model. In addition, we assessed the structural differences in preferences using stratified (subgroup) analysis. A significance threshold of 5\% was used to assess statistically significant differences.

For the ordinal outcome 'willingness to accept pain', we used an ordered panel logit model, assuming proportionality of odds between outcome levels. The levels weights were expressed as odds ratios (OR) with $95 \%$ confidence intervals.

\section{Results}

\subsection{Descriptive statistics}

A total of $1827 \mathrm{HCW}$ responded to the online survey, of which 18 did not meet the inclusion criteria. One third ( $=595,32.9 \%)$ indicated working outside the institutional setting and were thus excluded from the present analysis. Among the remaining $1214 \mathrm{HCWs}, 72.5 \%$ 
Working Paper. Preferences around vaccination among French health care workers

were nurses, $10.5 \%$ doctors, $9.1 \%$ nursing managers and $7.9 \%$ other professional groups

(including nurse assistants and midwives) (Table 2). Forty percent of respondents were younger than 40 years, $81.8 \%$ were female, $51.7 \%$ were vaccinated against influenza during the 2017-18

season $(78.1 \%, 48.0 \%, 60.9 \%$ and $18.4 \%$, respectively, among doctors, nurses, nursing managers and other groups) and $83.6 \%$ were up-to-date for pertussis vaccination. Most HCWs (83.5\%) declared trusting health authorities for vaccine information, while only $17.0 \%$ declared trusting information from the mass media. Most HCWs were favorable towards vaccination in general (93.2\%), and $83.5 \%$ towards influenza vaccination. A low, medium and high level of vaccine hesitancy was found for $25.0 \%, 6.1 \%$ and $23.1 \%$ of participants, respectively. Use of alternative medicine was reported by $47.2 \%$, and daily smoking, by $16.1 \%$ of participants. Only $11(0.91 \%)$ participants were students, therefore their responses were not analyzed separately.

\subsection{Stated preferences}

Overall, the participating HCWs accepted $58.0 \%$ of vaccination scenarios (range: $25.4 \%$ to $83.6 \%$ ). Between- and within-individual heterogeneity in vaccination acceptation was of the same magnitude (0.36 and 0.33, respectively) (Table 3). The scenario representing realistic influenza and pertussis vaccination situation was accepted by $74.2 \%$ and $81.4 \%$ of HCWs, respectively. The most commonly accepted maximal level of mild side effects was one day of redness and swelling at the injection site $(46.0 \%)$.

\subsubsection{Determinants of vaccine acceptance}

The overall importance of attributes is displayed in Figure 2. Safety issues had greatest influence on vaccination acceptance (normalized logworth $=100 \%$, reference) while attitude from the management did not have any significant impact. The attributes EFFECTIVENESS, 
Working Paper. Preferences around vaccination among French health care workers

INCENTIVE, INDIRECT PROTECTION, and COVERAGE had approximately equal influence (normalized logworth $=63 \%, 62 \%, 61 \%$, and 57\%, respectively).

The impact of each attribute's levels are details in Table 4. The level "epidemic risk estimated by health authorities" had higher effect than "cases among colleagues" (OR=1.89 vs.

$\mathrm{OR}=1.23,95 \%$ confidence intervals not overlapping). Vaccine acceptance was positively impacted by higher vaccine effectiveness (level " $90 \%$ for 3-5 y": OR=2.22) and, to a lesser extent, by longer duration of protection (“30\% for 3-5y”: OR=1.39). The attribute SAFETY included the levels with the highest absolute impact on vaccination acceptance, which were all negative. The strongest, negative impact (disutility) was observed for controversy $(\mathrm{OR}=0.04)$ and a confirmed severe side effect $(\mathrm{OR}=0.05)$, followed by "recent vaccine, no side effect known" $(\mathrm{OR}=0.30)$. Among inter-individual factors, the communication of "most colleagues vaccinated" and " $80 \%$ coverage" had positive impacts $(\mathrm{OR}=1.89$ and $\mathrm{OR}=1.45$, respectively), and the communication of " $30 \%$ coverage" had a small positive effect compared to "insufficient coverage" $(\mathrm{OR}=1.19)$. The potential for indirect protection showed the highest positive effects, with $\mathrm{OR}=2.41$ for "protection of family" and $\mathrm{OR}=2.34$ for "disease control". Incentives through badge or certificate, and threat had negative impacts $(\mathrm{OR}=0.47, \mathrm{OR}=0.57$ and $\mathrm{OR}=0.79$, respectively). A "message from management" was the only attribute level that did not show any significant impact on vaccination acceptance $(\mathrm{OR}=1.02)$. The results were robust to the exclusion of "straight-liners", that is, those always refusing or accepting the hypothetical vaccines, thus not contributing to the likelihood of the model (supplementary Table C1).

\subsubsection{Analysis of preference heterogeneity: interaction effects and subgroup analyses} Results of interaction models (Table 5) and subgroup analyses (supplementary material C, Tables C2 to C9) showed little variation in preferences according to HCW's background characteristics (e.g., gender, age, profession), but more pronounced differences according to 
Working Paper. Preferences around vaccination among French health care workers

vaccination attitudes. Preferences were not significantly different across gender and age accounted for only minor differences in preferences. Significant differences were found regarding vaccine effectiveness (lower utility of improved effectiveness among older HCWs) and vaccine safety profile (e.g., lower disutility from a so far safe but recent vaccine among 50-

65-year-old HCWs) (Table 5). Regarding profession, some differences were found such as a lower negative effect of "recent vaccine, no side effect" among nursing health managers (OR= $0.58,95 \%$-CI [0.37-0.93]; vs. OR=0.26 [0.22-0.31] among nurses) and a significantly positive impact of "message from the management" among nursing health managers (Table 5) and among doctors $(\mathrm{OR}=1.52,95 \%$-CI [1.00-2.32]; vs. $\mathrm{OR}=0.96$ [0.84-1.09] among nurses, Table C2). HCWs using, advising and / or consulting (for) alternative medicine experienced increased disutility from the levels "controversy" and "known, neuro effect" of the SAFETY attribute (Table 5).

Participants vaccinated against seasonal influenza during 2017-18 (N=628), those not vaccinated but vaccine-favorable in general $(\mathrm{N}=502)$, and those not vaccinated and vaccineunfavorable $(\mathrm{N}=76)$ accepted vaccination in $76.5 \%, 42.8 \%$ and $8.3 \%$ of scenarios, respectively. These results show strong consistence between revealed preferences (i.e., reported vaccination uptake) and stated preferences (i.e., hypothetical uptake). Not vaccinated and unfavorable participants tended to be younger, with higher prevalence of women and nurse assistants, while doctors, men and older participants were overrepresented in the vaccinated group. Table 5 show that this composite variable combining vaccine attitudes and practices account for largest variations in preferences. Stratified analyses according to this variable are displayed in supplementary Table C9 / Figure C1. Compared to vaccinated participants, those who were not vaccinated but vaccine-favorable were significantly more sensitive to improved and longer vaccine effectiveness (“90\% for 3-5y”: OR=2.84 vs. OR=1.59), but experienced less disutility from controversy $(\mathrm{OR}=0.05$ vs. $\mathrm{OR}=0.03)$, confirmed side effect $(\mathrm{OR}=0.07 \mathrm{vs}$. $\mathrm{OR}=0.04)$ and 
Working Paper. Preferences around vaccination among French health care workers

incentive through badge $(\mathrm{OR}=0.54$ vs. $\mathrm{OR}=0.35)$ (Table C9). By contrast, compared to the unvaccinated but vaccine-favorable group, participants who were not vaccinated and vaccineunfavorable showed substantially greater sensitivity to vaccine safety $(\mathrm{OR}=0.01$ for "confirmed side effects" and OR= 0.12 for "recent vaccine, no side effect"). They tended to be more

sensitive to the epidemic situation ( $\mathrm{OR}=4.67$ [1.04-20.99] for "cases among patients") and to social conformism $(\mathrm{OR}=3.68$ [0.87-15.60] for the level " $80 \%$ of French HCWs vaccinated"), less sensitive to potential for indirect protection for patients and family except for disease control $(\mathrm{OR}=2.13[0.39-11.72])$, and experience greater disutility from incentives $(\mathrm{OR}=0.27$ [0.071.08] for the level "badge").

\subsection{Determinants of willingness to accept pain (ordinal outcome)}

Regarding the ordinal outcome maximal acceptable minor side effect (willingness to accept pain), most attributes' levels were not significantly associated with vaccination acceptance and the associated OR were in general close to 1 (Table 4). However, significant effects were found for "high epidemic risk" $(\mathrm{OR}=1.49)$, "controversy" $(\mathrm{OR}=0.76)$, " $90 \%$ effectiveness for 3-5 years" $(\mathrm{OR}=1.24)$, “30\% coverage" $(\mathrm{OR}=0.82)$ and "protection of the family" $(\mathrm{OR}=1.43)$.

\section{Discussion}

\subsection{Summary of results and interpretation}

We used a DCE to quantify the weights that French HCWs attach to known factors of vaccine decision. For a disease comparable to influenza or pertussis, we found impacts from listed in decreasing order of importance - issues around vaccine safety (negative), improved vaccine effectiveness, incentives (negative), potential for indirect protection, vaccine coverage, 
Working Paper. Preferences around vaccination among French health care workers

and information on epidemic risk. Hierarchical injunction had a positive impact only among nursing health managers and doctors. While the average frequency of acceptance substantially varied between subgroups, preference weights were relatively homogeneous. Among HCWs who were not vaccinated against seasonal influenza, those favorable vs. those unfavorable to

vaccination in general could be distinguished by a preference for higher vaccine effectiveness among the first group $v s$. a particularly strong sensitivity for safety-related issues among the second group.

Our main hypothesis was that disease risks and vaccination safety were the most important predictors of vaccination decisions. Our results confirm this a priori for issues around vaccine safety, with OR well below 0.5 and down to 0.04 , which is close to systematic refusal of vaccination. While such a strong impact from a confirmed side effect can easily be understood and confirm previous results in different contexts (Luyten et al., 2019; Verelst et al., 2018), the even more negative impact from a controversy is surprising. It is theoretically possible that participants imagined that the controversy carried on something worse than a marginally increased risk of a lifelong neurological disease, but it is also possible that controversy aversion per se came into play. Controversies have played a crucial role in the public perception of vaccination over the last few decades in France, spanning from vaccines against hepatitis B and pandemic influenza to HPV and more generally vaccines containing aluminium adjuvants. From an economic standpoint, disutility experienced from the absence of reliable and credible information about risk is related to ambiguity aversion (Berger et al., 2013), a concept that has been shown to negatively affect prevention behaviors (Han et al., 2009) or treatment decisions (Berger et al., 2013). Identifying interventions that can moderate this negative impact of controversies should be of high priority for public health. This is a challenge, as simple delivery of counter-information has been found to aggravate vaccine safety concerns (Pluviano et al., 2017). The substantial negative impact from the information that the vaccine is recent (albeit so 
far safe) may appear surprising, but corresponds to the ranking between old, well-known and newly recommended vaccines, recently described in France (Humez et al., 2017). As described by Slovic in a seminal paper (Slovic, 1987), tolerance of new hypothetical risks is usually lower than that of old, well-known ones. In addition, lack of trust in health authorities and

pharmacovigilence, previously described among European healthcare workers (Karafillakis et al., 2016), may contribute to explain the result. Overall, these results reflect an impressively negative perception of uncertainty around safety, which has also been described among French university students (Seanehia et al., 2017). Whether this is a specificity of the French population, as suggested by an international comparison of the consent to the simplistic affirmation "vaccines are safe" (Larson et al., 2016) requires further investigation.

The occurrence of disease cases among patients and colleagues, or the estimation of a higher epidemic risk by health authorities had a relatively low impact on vaccination acceptance $(\mathrm{OR}<2)$, which may be explained by the fact that the hypothetical disease was presented as mild, with complications being limited to vulnerable persons. However, the announcement of an epidemic risk tended to have strong impact among vaccine-unfavorable participants, suggesting that communication on an exceptional epidemic risk can be an external cue for vaccination, despite hesitancy (Chang, 2016).

The third vaccine-related attribute, improved (duration of) vaccine effectiveness, showed a substantial impact $(\mathrm{OR}>2)$ on vaccine acceptance. This factor is often neglected in the debate around vaccine hesitancy among health care workers, although disease risk perception is necessarily modulated by perception of benefits from vaccination (Becker, 1974) and low effectiveness has been described as a barrier to vaccine uptake (Doumont and Libion, 2007; Hakim et al., 2011). Our results suggest that influenza vaccine acceptance among HCWs could increase, once vaccines with an effectiveness that is less impacted by strain variations will be available. 
The inter-individual attributes were found to have a substantial impact on HCWs' vaccine

acceptance. The strong impact from a potential indirect protection suggests that such an argument may partially compensate for the low perceived risk related to the disease (Seanehia et al., 2017). Moreover, directly mentioning patients as a group to protect tended to have less

impact than referring to collective disease control, in particular among vaccine-unfavorable HCWs. While altruism has been described as a motivating factor for vaccination (Prematunge et al., 2012; Shim et al., 2012), it may not be appropriate to request or incite it and the offer to participate in a collective effort of disease control may more easily be heard. Further research is needed regarding the development of targeted communication content about indirect protection. We found that doctors' relative weight for indirect protection was lower compared to nurses, which may reflect the fact that the reference level "protect one-self" already is a greater motivator in this group.

Our results suggest that most participating HCWs might be prone to normative social influence, with the information about colleagues being vaccinated or a high coverage among HCWs motivating vaccination acceptance. A similar impact was observed among French university students (Seanehia et al., 2017). Social conformism is part of heuristics that are increasingly recognized as determinants of health-related decisions (Gigerenzer, 2008). It is important to note that we could not identify any subgroup in which a "high coverage" attribute level had negative impact on acceptance, thus rejecting free-riding motives among HCWs, in line with results found in previous DCEs among US parents (Gidengil et al., 2012), the Belgian general population (Verelst et al., 2018), and South African adult population (Verelst et al., 2019). Social benefits of vaccination were explicitly addressed in our experiment, which following Betsch et al. (2013) - may have prevented free-riding. Finally, as hypothesized, the commonly used formulation of "insufficient coverage" was the least attractive for hospital 
HCWs. This could point to an aversion against an unsuccessful vaccination program

(Prematunge et al., 2012).

Our study allowed pretesting interventions to increase vaccine acceptance. While a message from the management did not have any impact except among doctors, any form of incentive event had a substantial negative impact on vaccine acceptance $(\mathrm{OR}<0.6)$. This sheds

light on the motivation of care professionals. Protecting the patient is one primary goal of the profession - also referred as an 'intrinsic motivation'(Deci, 1972) - and any additional incentive suggesting HCW needs to be rewarded for expected behavior may undermine this intrinsic motivation and thus be negatively perceived (Frey, 1994). For instance, a badge that would allow distinguishing oneself from colleagues may be seen as overjustified (Tang and Hall, 1995), under the assumption that intrinsic and/or social motivations towards vaccination prevail initially. In this respect, our results do not support the assumption that external (non-monetary) incentives could complement intrinsic motivation or altruistic motives (Sicsic et al., 2012). Note that we have limited our tool to incentives currently used in France. Others, such as financial incentives, would require additional analysis.

The use of an ordinal outcome representing the maximal acceptable minor side effect allowed us some insight into willingness to accept (WTA) pain/discomfort for vaccination, thus reflecting how far different attributes go beyond personal utility. Most attribute levels showed low or no impact on WTA increasing pain, which suggest that they were part of the personal utility function. However, high epidemic risk according to health authorities, controversy, improved vaccine performance, and protection of the family had a significant impact on WTA side effects, thus suggesting that a motivation beyond personal utility may be at play. This refers to the distinction made by A. Sen between sympathy (within personal utility) and commitment (beyond personal utility) and suggests that altruism can partially be captured by willingness-topay studies (Shiell and Rush, 2003). 


\subsection{Study limitations}

Our study has several limitations. First of all, our study sample was not a representative

overrepresented. For example, physicians and nursing managers, who are more favorable towards vaccination than other professional groups in our sample, were overrepresented. Prevalence estimates from our study (e.g., average stated vaccination intentions) therefore cannot be interpreted as prevalence among French HCWs. A second issue is that we cannot exclude that stated preferences substantially vary across classes of some unobserved variables, implying that our combined estimates would not be valid. If study participation was correlated to these theoretically unobserved variables, the stated preferences could even be substantially over- or underestimated. To explore this risk, we used a wide range of personal characteristics in interaction analyses. We found substantial variation only for a combination of two variables of vaccine status and perception: vaccinated, unvaccinated but favorable and unvaccinated and unfavorable participants (see Table 5, and supplementary Table C9), suggesting that the inclusion of a more representative $\mathrm{HCW}$ sample with lower vaccine coverage and less favorable opinion would have led to higher coefficients (in absolute terms) in combined estimates for the attributes "EPI", "SAFETY", "INCENTIVE", and lower coefficients for the attributes "EFFECTIVENESS" and "INDIRECT PROTECTION". To attenuate the limitation by nonrepresentative sampling, we show in this manuscript the stratified analyses that yielded the most important variation in preferences.

Caution is needed in interpreting our results because of the hypothetical nature of the choices. Hypothetical bias is a concern in stated preference surveys when respondents tend either to overestimate the uptake of hypothetical programs and/or the willingness to pay, because they 
Working Paper. Preferences around vaccination among French health care workers

do not face the opportunity costs directly (Loomis, 2011). We tried to reduce the prevalence of hypothetical bias ex ante by asking respondents to make choices as honestly as possible, as in a real-life situation. Finally, our empirical models did not account for decision heuristics such as attribute non-attendance, where some respondents base their decision considering only a subset of attributes.

Our experimental design has some limitations. First, we used a main-effects D-efficient design, which is not optimal for estimating non-linear models with random intercept. We have analyzed the properties of our design a posteriori and found that our design was $81 \%$ D-efficient compared to the best possible design for a random intercept logit model using our estimated model' parameters as priors. Thus, the loss in statistical efficiency is reasonable. Second, our experiment was not designed to test interactions effects between attributes. However, we had not a priori assumptions regarding how specific attributes would interact with each other. Estimation of non-linear in attributes utility functions in the context of vaccines should be included in further research. We believe that qualitative work may help defining such interactions a priori. Finally, the number of choices sets presented to each respondent (i.e. 16) was quite high, which could have resulted in respondents' fatigue. We investigated this effect using heteroskedastic probit models by including the position of the choice task (i.e., early phase: task 1 to 6 , middle phase: task 7 to 12 , and late phase: task 13 to 16) as determinant of the variance of the error term (Campbell et al., 2015). We did not find any significant impact of the position of the choice task on the scale of utility (results are available upon request), thus rejecting the assumption of fatigue or decrease in survey engagement. This finding is consistent with previous research conducted in various fields of non-market valuation such as transportation / marketing (Hess et al., 2012) and health (Bech et al., 2011), which did not find decreasing trend in response consistency (scale) across choice tasks. Finally, we cannot exclude that a qualitative study prior to tool development would have revealed barriers and levers that drive vaccine decisions 

specifically among French HCWs and which have not yet been described in the published literature.

\subsection{Practical Implications}

Our results have some implications for vaccine communication towards HCWs. How well they can be generalized from France to other countries requires further investigation. A clear recommendation would carry on clear and factual statements about vaccine safety profiles. Explaining drugs safety appears crucial, particularly how international efforts allow quickly knowing the safety profile of a new vaccine. The communication on scientific uncertainty is difficult, but controversy is clearly worse (Betsch et al., 2013; Seanehia et al., 2017). Another recommendation would carry on avoiding the notion of "insufficient coverage" and rather using positive approaches such as storytelling about vaccinated colleagues and providing factual information about low but continuously increasing coverage. Our results suggest that explaining indirect protection and social benefits may in part counterbalance low disease risk perception, while emphasizing participation in disease control may be more effective than requesting altruism.

Using incentives such as badges should be avoided in vaccination promotion to HCWs, as it may even have negative impact, in particular among those who usually get vaccinated. By contrast, a clear argumentation and communication on the relatively high impact that can be expected from high coverage given indirect protection - even with vaccines of limited direct effectiveness - may increase motivation for vaccination, in particular among HCWs who are unvaccinated but favorable to vaccination in general. 
Finally, in order to improve vaccination among HCWs who are unfavorable towards

601

602

603

604

605

606

607

608

609

610

611

612

613

614

615

616

617

618

619

620

vaccination, our study suggests that beliefs about the meaning of uncertainty and controversy need to be addressed in priority and further research is required in order to develop appropriate (targeted) communication contents.

\subsection{Conclusion}

Using a DCE among French hospital HCWs, we evaluated the relative importance of individual and inter-individual level characteristics of vaccination scenarios against frequent, usually mild disease that can be severe among vulnerable groups, such as influenza and pertussis. We identified the dominant negative impact of controversies and the notion of "recent vaccines"; distinct preferences among HCWs who recently have refused influenza vaccination and according to their general attitude towards vaccination; and a pronounced negative impact from proposing incentives such as wearing badges "I'm vaccinated". We suggest optimizing the communication on indirect protection by emphasizing disease control rather than altruism and stimulating positive social conformism. These results illustrate that DCE studies for specific vaccine programs and target groups help understanding vaccination decisions in a refined way, particularly by exploring preferences among specific subgroups and by pretesting interventions. 


\section{References}

Bech, M., Kjaer, T., Lauridsen, J., 2011. Does the number of choice sets matter? Results from a web survey applying a discrete choice experiment. Health Econ. 20, 273-286. https://doi.org/10.1002/hec.1587

Becker, M.H., 1974. The Health Belief Model and Sick Role Behavior. Health Educ. Monogr. 2, 409-419. https://doi.org/10.1177/109019817400200407

Berger, L., Bleichrodt, H., Eeckhoudt, L., 2013. Treatment decisions under ambiguity. J. Health Econ. 32, 559-569. https://doi.org/10.1016/j.jhealeco.2013.02.001

Betsch, C., Böhm, R., Korn, L., 2013. Inviting free-riders or appealing to prosocial behavior? game-theoretical reflections on communicating herd immunity in vaccine advocacy. Health Psychol. Off. J. Div. Health Psychol. Am. Psychol. Assoc. 32, 978-985. https://doi.org/10.1037/a0031590

Boey, L., Bral, C., Roelants, M., De Schryver, A., Godderis, L., Hoppenbrouwers, K., Vandermeulen, C., 2018. Attitudes, believes, determinants and organisational barriers behind the low seasonal influenza vaccination uptake in healthcare workers - A crosssectional survey. Vaccine 36, 3351-3358. https://doi.org/10.1016/j.vaccine.2018.04.044

Bonmarin, I., Belchior, E., Lévy-Bruhl, D., 2015. Impact of influenza vaccination on mortality in the French elderly population during the 2000-2009 period. Vaccine 33, 1099-1101. https://doi.org/10.1016/j.vaccine.2015.01.023

Bridges, J.F.P., Hauber, A.B., Marshall, D., Lloyd, A., Prosser, L.A., Regier, D.A., Johnson, F.R., Mauskopf, J., 2011. Conjoint analysis applications in health--a checklist: a report of the ISPOR Good Research Practices for Conjoint Analysis Task Force. Value Health J. Int. Soc. Pharmacoeconomics Outcomes Res. 14, 403-413. https://doi.org/10.1016/j.jval.2010.11.013

Calugar, A., Ortega-Sánchez, I.R., Tiwari, T., Oakes, L., Jahre, J.A., Murphy, T.V., 2006. Nosocomial pertussis: costs of an outbreak and benefits of vaccinating health care workers. Clin. Infect. Dis. Off. Publ. Infect. Dis. Soc. Am. 42, 981-988. https://doi.org/10.1086/500321

Campbell, D., Boeri, M., Doherty, E., George Hutchinson, W., 2015. Learning, fatigue and preference formation in discrete choice experiments. J. Econ. Behav. Organ. 119, 345363. https://doi.org/10.1016/j.jebo.2015.08.018

Canning, H.S., Phillips, J., Allsup, S., 2005. Health care worker beliefs about influenza vaccine and reasons for non-vaccination--a cross-sectional survey. J. Clin. Nurs. 14, 922-925. https://doi.org/10.1111/j.1365-2702.2005.01190.x

Chang, C., 2016. Behavioral Recommendations in Health Research News as Cues to Action: Self-Relevancy and Self-Efficacy Processes. J. Health Commun. 21, 954-968. https://doi.org/10.1080/10810730.2016.1204377

Clark, M.D., Determann, D., Petrou, S., Moro, D., Bekker-Grob, E.W. de, 2014. Discrete Choice Experiments in Health Economics: A Review of the Literature. PharmacoEconomics 32, 883-902. https://doi.org/10.1007/s40273-014-0170-x

Deci, E.L., 1972. Intrinsic motivation, extrinsic reinforcement, and inequity. J. Pers. Soc. Psychol. 22, 113-120. https://doi.org/10.1037/h0032355

Determann, D., Korfage, I.J., Fagerlin, A., Steyerberg, E.W., Bliemer, M.C., Voeten, H.A., Richardus, J.H., Lambooij, M.S., de Bekker-Grob, E.W., 2016. Public preferences for 
vaccination programmes during pandemics caused by pathogens transmitted through respiratory droplets - a discrete choice experiment in four European countries, 2013. Euro Surveill. Bull. Eur. Sur Mal. Transm. Eur. Commun. Dis. Bull. 21. https://doi.org/10.2807/1560-7917.ES.2016.21.22.30247

Dorribo, V., Lazor-Blanchet, C., Hugli, O., Zanetti, G., 2015. Health care workers' influenza vaccination: motivations and mandatory mask policy. Occup. Med. Oxf. Engl. 65, 739745. https://doi.org/10.1093/occmed/kqv116

Doumont, D., Libion, F., 2007. Vaccination contre la grippe auprès des professionnels de santé : tour d'horizon des pays développés, quelles recommandations pour quelle efficacité ?

Fine, P., Eames, K., Heymann, D.L., 2011. "Herd immunity”: a rough guide. Clin. Infect. Dis. Off. Publ. Infect. Dis. Soc. Am. 52, 911-916. https://doi.org/10.1093/cid/cir007

Frey, B.S., 1994. How Intrinsic Motivation is Crowded out and in. Ration. Soc. 6, 334-352. https://doi.org/10.1177/1043463194006003004

Gidengil, C., Lieu, T.A., Payne, K., Rusinak, D., Messonnier, M., Prosser, L.A., 2012. Parental and societal values for the risks and benefits of childhood combination vaccines. Vaccine 30, 3445-3452. https://doi.org/10.1016/j.vaccine.2012.03.022

Gigerenzer, G., 2008. Why Heuristics Work. Perspect. Psychol. Sci. J. Assoc. Psychol. Sci. 3, 20-29. https://doi.org/10.1111/j.1745-6916.2008.00058.x

Gil, H., Bailly, P., Meaux-Ruault, N., Clement, I., Floret, N., Guiot, A., Manteaux, C., Talon, D., Magy, N., Dupond, J.L., 2006. La vaccination antigrippale du personnel hospitalier. Enquête de prévalence au CHU de Besançon, hiver 2003-2004. Rev. Médecine Interne 27, 5-9. https://doi.org/10.1016/j.revmed.2005.09.007

Greene, M.T., Fowler, K.E., Ratz, D., Krein, S.L., Bradley, S.F., Saint, S., 2018. Changes in Influenza Vaccination Requirements for Health Care Personnel in US Hospitals. JAMA Netw. Open 1, e180143-e180143. https://doi.org/10.1001/jamanetworkopen.2018.0143

Guthmann, J.-P., Fonteneau, L., Ciotti, C., Bouvet, E., Pellissier, G., Lévy-Bruhl, D., Abiteboul, D., 2012. Vaccination coverage of health care personnel working in health care facilities in France: results of a national survey, 2009. Vaccine 30, 4648-4654. https://doi.org/10.1016/j.vaccine.2012.04.098

Hakim, H., Gaur, A.H., McCullers, J.A., 2011. Motivating factors for high rates of influenza vaccination among healthcare workers. Vaccine 29, 5963-5969.

https://doi.org/10.1016/j.vaccine.2011.06.041

Han, P.K.J., REEVE, B.B., MOSER, R.P., KLEIN, W.M.P., 2009. Aversion to Ambiguity Regarding Medical Tests and Treatments: Measurement, Prevalence, and Relationship to Sociodemographic Factors. J. Health Commun. 14, 556-572. https://doi.org/10.1080/10810730903089630

Hastings, G., Stead, M., Webb, J., 2004. Fear appeals in social marketing: Strategic and ethical reasons for concern. Psychol. Mark. 21, 961-986. https://doi.org/10.1002/mar.20043

Hayward, A.C., Harling, R., Wetten, S., Johnson, A.M., Munro, S., Smedley, J., Murad, S., Watson, J.M., 2006. Effectiveness of an influenza vaccine programme for care home staff to prevent death, morbidity, and health service use among residents: cluster randomised controlled trial. BMJ 333, 1241. https://doi.org/10.1136/bmj.39010.581354.55

Hess, S., Hensher, D.A., Daly, A., 2012. Not bored yet - Revisiting respondent fatigue in stated choice experiments. Transp. Res. Part Policy Pract. 46, 626-644. 
https://doi.org/10.1016/j.tra.2011.11.008

Humez, M., Le Lay E, Jestin C, Perrey C, 2017. Obligation vaccinale : résultats d'une étude qualitative sur les connaissances et perceptions de la population générale en France. Vaccination des jeunes enfants : des données pour mieux comprendre l'action publique. Bull Epidémiol Hebd Hors-série Vaccination.

Janus, K., 2010. Managing motivation among health care professionals. Adv. Health Care Manag. 9, 47-77. https://doi.org/10.1108/S1474-8231(2010)0000009007

Johnson, P., Bancroft, T., Barron, R., Legg, J., Li, X., Watson, H., Naeim, A., Watkins, A., Marshall, D.A., 2014. Discrete choice experiment to estimate breast cancer patients' preferences and willingness to pay for prophylactic granulocyte colony-stimulating factors. Value Health J. Int. Soc. Pharmacoeconomics Outcomes Res. 17, 380-389. https://doi.org/10.1016/j.jval.2014.01.002

Jorgensen, P., Mereckiene, J., Cotter, S., Johansen, K., Tsolova, S., Brown, C., 2018. How close are countries of the WHO European Region to achieving the goal of vaccinating $75 \%$ of key risk groups against influenza? Results from national surveys on seasonal influenza vaccination programmes, 2008/2009 to 2014/2015. Vaccine 36, 442-452. https://doi.org/10.1016/j.vaccine.2017.12.019

Karafillakis, E., Dinca, I., Apfel, F., Cecconi, S., Würz, A., Takacs, J., Suk, J., Celentano, L.P., Kramarz, P., Larson, H.J., 2016. Vaccine hesitancy among healthcare workers in Europe: A qualitative study. Vaccine 34, 5013-5020. https://doi.org/10.1016/j.vaccine.2016.08.029

Lancsar, E., Louviere, J., Flynn, T., 2007. Several methods to investigate relative attribute impact in stated preference experiments. Soc. Sci. Med. 64, 1738-1753. https://doi.org/10.1016/j.socscimed.2006.12.007

Larson, H.J., de Figueiredo, A., Xiahong, Z., Schulz, W.S., Verger, P., Johnston, I.G., Cook, A.R., Jones, N.S., 2016. The State of Vaccine Confidence 2016: Global Insights Through a 67-Country Survey. EBioMedicine 12, 295-301. https://doi.org/10.1016/j.ebiom.2016.08.042

Loomis, J., 2011. What's to Know About Hypothetical Bias in Stated Preference Valuation Studies? J. Econ. Surv. 25, 363-370. https://doi.org/10.1111/j.1467-6419.2010.00675.x

Lugo, N.R., 2007. Will carrots or sticks raise influenza immunization rates of health care personnel? Am. J. Infect. Control 35, 1-6. https://doi.org/10.1016/j.ajic.2006.10.004

Luyten, J., Kessels, R., Atkins, K.E., Jit, M., van Hoek, A.J., 2019. Quantifying the public's view on social value judgments in vaccine decision-making: A discrete choice experiment. Soc. Sci. Med. 1982 228, 181-193. https://doi.org/10.1016/j.socscimed.2019.03.025

MacDonald, N.E., SAGE Working Group on Vaccine Hesitancy, 2015. Vaccine hesitancy: Definition, scope and determinants. Vaccine 33, 4161-4164. https://doi.org/10.1016/j.vaccine.2015.04.036

Maltezou, H.C., Poland, G.A., 2014. Vaccination policies for healthcare workers in Europe. Vaccine 32, 4876-4880. https://doi.org/10.1016/j.vaccine.2013.10.046

Mereckiene, J., Cotter, S., Nicoll, A., Lopalco, P., Noori, T., Weber, J., D’Ancona, F., LevyBruhl, D., Dematte, L., Giambi, C., Valentiner-Branth, P., Stankiewicz, I., Appelgren, E., O Flanagan, D., VENICE project gatekeepers group, 2014. Seasonal influenza immunisation in Europe. Overview of recommendations and vaccination coverage for three seasons: pre-pandemic (2008/09), pandemic (2009/10) and post-pandemic 
(2010/11). Euro Surveill. Bull. Eur. Sur Mal. Transm. Eur. Commun. Dis. Bull. 19, 20780.

Paulussen, T.G.W., Hoekstra, F., Lanting, C.I., Buijs, G.B., Hirasing, R.A., 2006. Determinants of Dutch parents' decisions to vaccinate their child. Vaccine 24, 644-651. https://doi.org/10.1016/j.vaccine.2005.08.053

Pluviano, S., Watt, C., Sala, S.D., 2017. Misinformation lingers in memory: Failure of three provaccination strategies. PLOS ONE 12, e0181640. https://doi.org/10.1371/journal.pone.0181640

Prematunge, C., Corace, K., McCarthy, A., Nair, R.C., Pugsley, R., Garber, G., 2012. Factors influencing pandemic influenza vaccination of healthcare workers--a systematic review. Vaccine 30, 4733-4743. https://doi.org/10.1016/j.vaccine.2012.05.018

Reed Johnson, F., Lancsar, E., Marshall, D., Kilambi, V., Mühlbacher, A., Regier, D.A., Bresnahan, B.W., Kanninen, B., Bridges, J.F.P., 2013. Constructing Experimental Designs for Discrete-Choice Experiments: Report of the ISPOR Conjoint Analysis Experimental Design Good Research Practices Task Force. Value Health 16, 3-13. https://doi.org/10.1016/j.jval.2012.08.2223

Rosenstock, I.M., 1974. The Health Belief Model and Preventive Health Behavior. Health Educ. Monogr. 2, 354-386. https://doi.org/10.1177/109019817400200405

Ryan, M., Gerard, K., 2003. Using discrete choice experiments to value health care programmes: current practice and future research reflections. Appl. Health Econ. Health Policy. 2, $55-64$.

Santé Publique France, 2019. Couverture vaccinale antigrippale chez les professionnels de santé. Bulletin de santé publique. Available at https://www.santepubliquefrance.fr/determinants-de$\underline{\text { sante/vaccination/documents/bulletin-national/bulletin-de-sante-publique-vaccination.- }}$ octobre-2019. Last accessed 25 November, 2019

Seanehia, J., Treibich, C., Holmberg, C., Müller-Nordhorn, J., Casin, V., Raude, J., Mueller, J.E., 2017. Quantifying population preferences around vaccination against severe but rare diseases: A conjoint analysis among French university students, 2016. Vaccine 35, 2676-2684. https://doi.org/10.1016/j.vaccine.2017.03.086

Setbon, M., Raude, J., 2010. Factors in vaccination intention against the pandemic influenza A/H1N1. Eur. J. Public Health 20, 490-494. https://doi.org/10.1093/eurpub/ckq054

Shiell, A., Rush, B., 2003. Can willingness to pay capture the value of altruism? An exploration of Sen's notion of commitment. J. Socio-Econ. 32, 647-660. https://doi.org/10.1016/j.socec.2003.10.003

Shim, E., Chapman, G.B., Townsend, J.P., Galvani, A.P., 2012. The influence of altruism on influenza vaccination decisions. J. R. Soc. Interface 9, 2234-2243. https://doi.org/10.1098/rsif.2012.0115

Sicsic, J., Le Vaillant, M., Franc, C., 2012. Intrinsic and extrinsic motivations in primary care: an explanatory study among French general practitioners. Health Policy Amst. Neth. 108, 140-148. https://doi.org/10.1016/j.healthpol.2012.08.020

Slovic, P., 1987. Perception of risk. Science 236, 280-285.

Tang, S.-H., Hall, V.C., 1995. The overjustification effect: A meta-analysis. Appl. Cogn. Psychol. 9, 365-404. https://doi.org/10.1002/acp.2350090502

Valour, F., Maulin, L., Ader, F., Perpoint, T., Champagne, H., David, G., Boibieux, A., Biron, 
F., Peyramond, D., Chidiac, C., 2007. Vaccination contre la grippe: résultats d'une enquête sur la couverture vaccinale du personnel hospitalier à l'hôpital de la CroixRousse (hôpitaux de Lyon). Médecine Mal. Infect. 37, 51-60. https://doi.org/10.1016/j.medmal.2006.10.007

Verelst, F., Kessels, R., Delva, W., Beutels, P., Willem, L., 2019. Drivers of vaccine decisionmaking in South Africa: A discrete choice experiment. Vaccine 37, 2079-2089. https://doi.org/10.1016/j.vaccine.2019.02.056

Verelst, F., Willem, L., Kessels, R., Beutels, P., 2018. Individual decisions to vaccinate one's child or oneself: A discrete choice experiment rejecting free-riding motives. Soc. Sci. Med. 1982 207, 106-116. https://doi.org/10.1016/j.socscimed.2018.04.038

Verger, P., 2017. Les médecins face à la crise de confiance dans la vaccination en France. Médecine 13, 110-114. https://doi.org/10.1684/med.2017.181

Visser, O., Hulscher, M.E.J.L., Antonise-Kamp, L., Akkermans, R., van der Velden, K., Ruiter, R.A.C., Hautvast, J.L.A., 2018. Assessing determinants of the intention to accept a pertussis cocooning vaccination: A survey among healthcare workers in maternity and paediatric care. Vaccine 36, 736-743. https://doi.org/10.1016/j.vaccine.2017.12.021

Wooldridge, J.M., 2002. Econometric Analysis of Cross Section and Panel Data. MIT Press, Cambridge, Massachusetts. 


\section{Tables}

Table 1. Attributes and levels in the discrete choice experiment

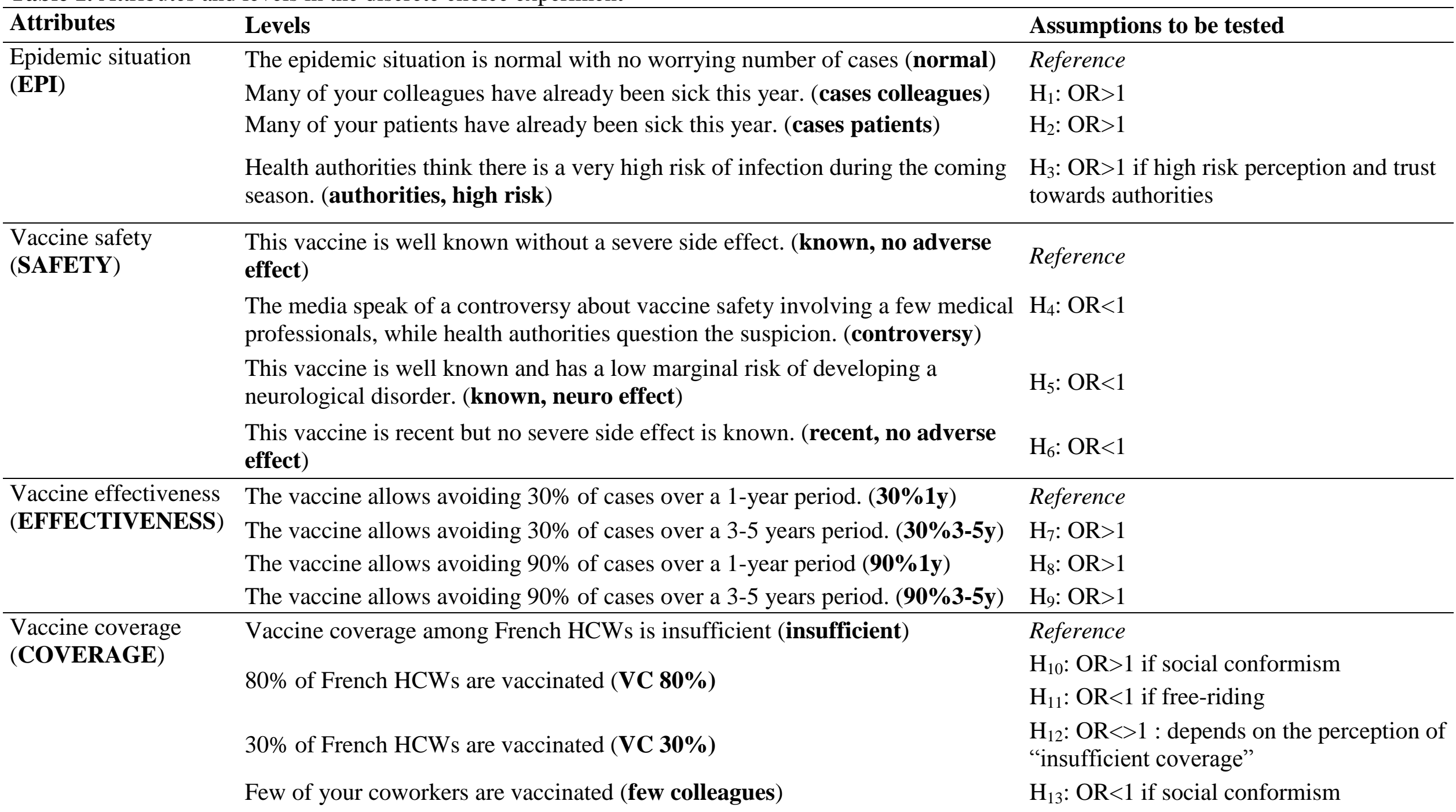


Most of your coworkers are vaccinated (Most colleagues)

Potential for indirect

protection

(INDIRECT

PROTECTION)

The vaccine provides only individual protection (individual only)

Vaccinating yourself allows participation in disease control. (disease control)

Vaccinating yourself will indirectly protect vulnerable people in your family. (family)

Vaccinating yourself will indirectly protect your patients. (patients)

Incentive There is no specific action proposed. (no action)

(INCENTIVE)

If vaccinated, you can wear a badge "I'm vaccinated". (badge)

If your department achieved vaccine coverage above $60 \%$, you will receive a certificate for communication. (certificate)

If the service vaccine coverage is low, hygiene rules will be reinforced. (hygiene)

\begin{tabular}{ll}
\hline $\begin{array}{l}\text { Attitude of the } \\
\text { management }\end{array}$ & The management does not give any message regarding this vaccination (no \\
(MANAGEMENT) & message)
\end{tabular}

The management asks the HCW to get vaccinated to protect patients and avoid absenteeism (message)
$\mathrm{H}_{14}: \mathrm{OR}>1$ if social conformism

$\mathrm{H}_{15}$ : $\mathrm{OR}<1$ if free-riding

Reference

$\mathrm{H}_{16}$ : $\mathrm{OR}>1$ : If altruistic attitude

$\mathrm{H}_{17}: \mathrm{OR}>1$ : If altruistic attitude

$\mathrm{H}_{18}: \mathrm{OR}>1$ : If altruistic attitude

Reference

$\mathrm{H}_{19}$ : $\mathrm{OR}>1$ if sensitivity to a reward or to an exterior brand of vaccination

$\mathrm{H}_{20}$ : $\mathrm{OR}<1$ if negative relationship

between intrinsic motivation and external incentive

$\mathrm{H}_{21}$ : OR> 1 if sensitivity to the reputation of the service

$\mathrm{H}_{22}$ : $\mathrm{OR}<1$ if negative relationship between intrinsic motivation and external incentive

$\mathrm{H}_{23}$ : OR>1 if sensitivity to external pressure and constraints

$\mathrm{H}_{24}$ : $\mathrm{OR}<1$ if 'protest' against increased constraints and control

\section{Reference}

$\mathrm{H}_{25}$ : $\mathrm{OR}>1$ if sensitivity to external

injunction

$\mathrm{H}_{26}$ : $\mathrm{OR}<1$ if disutility from hierarchical pressure or injunction

HCW: health care worker

OR: odds ratio 
Table 2. Participant characteristics. Survey among 1214 hospital health care workers in France, June-September 2018.

\begin{tabular}{|c|c|c|}
\hline & $\mathrm{n}$ & $\%$ \\
\hline \multicolumn{3}{|l|}{ Gender: } \\
\hline Women & 993 & 81.8 \\
\hline Men & 221 & 18.2 \\
\hline \multicolumn{3}{|l|}{ Age groups (years): } \\
\hline $18-29$ & 188 & 15.48 \\
\hline $30-49$ & 603 & 49.67 \\
\hline $50-65+$ & 423 & 34.84 \\
\hline \multicolumn{3}{|l|}{ Profession: } \\
\hline Nurse & 880 & 72.49 \\
\hline Doctor & 128 & 10.54 \\
\hline Nursing health manager & 110 & 9.06 \\
\hline Other health care profession & 96 & 7.41 \\
\hline \multicolumn{3}{|l|}{ Vaccine hesitancy: } \\
\hline No hesitancy & 535 & 45.8 \\
\hline Low hesitancy & 292 & 25.00 \\
\hline Medium hesitancy & 71 & 6.08 \\
\hline Strong hesitancy & 270 & 23.12 \\
\hline \multicolumn{3}{|l|}{ Influenza vaccination during 2017-18 season: } \\
\hline Do not know & 8 & 0.66 \\
\hline No & 578 & 47.61 \\
\hline Yes & 628 & 51.73 \\
\hline \multicolumn{3}{|l|}{ Trust in health authorities *: } \\
\hline \multicolumn{3}{|l|}{ Trust in vaccine information from media $*$ : } \\
\hline Yes & 206 & 17.0 \\
\hline \multicolumn{3}{|c|}{ Trust in vaccine information from pharmaceutical industrial *: } \\
\hline Yes & 254 & 20.9 \\
\hline \multicolumn{3}{|l|}{ Favorable to vaccination in general *: } \\
\hline Yes & 1132 & 93.25 \\
\hline \multicolumn{3}{|c|}{ Unfavorable to influenza vaccination in particular $* *$ : } \\
\hline Yes & 200 & 16.48 \\
\hline \multicolumn{3}{|l|}{ Smokes daily: } \\
\hline Yes & 196 & 16.14 \\
\hline Uses alternative medicine: & 573 & 47.20 \\
\hline $\begin{array}{c}\text { Uses homeopathic protection against flu: } \\
\text { Yes }\end{array}$ & 194 & 15.98 \\
\hline
\end{tabular}

\footnotetext{
* Replies were given on a Likert-scale with the modalities "strongly agree/somewhat agree/ somewhat disagree/ strongly disagree". 'Strongly agree and 'somewhat agree' were collapsed into one category 'yes' for analysis, vs. 'no' ('somewhat disagree/ strongly disagree').

** Coded 'yes' if participants mentioned "influenza vaccine" when asked: "Are your unfavorable to a vaccination in particular?" / "If yes, which?"
} 
Table 3. Vaccination acceptance statistics in the discrete choice experiment. Survey among 1214 hospital health care workers in France, June-September 2018.

Total number of responses $\quad \mathrm{N}=19,424$

$\begin{array}{ll}\text { Between variability in acceptance (SD) } & 0.333\end{array}$

$\begin{array}{ll}\text { Within variability in acceptance (SD) } & 0.365\end{array}$

Straight-liners $^{\mathrm{a}}(\mathrm{n}, \%) \quad 355 \quad 29.24$

- Always accepting the hypothetical vaccines (n, \% $\quad 235 \quad 19.36$

- Always refusing the hypothetical vaccines (n, \%) $\quad 120 \quad 9.88$

\begin{tabular}{lll}
\hline Overall vaccination acceptance $(\mathbf{n}, \%)$ & 11,270 & 58.0
\end{tabular}

- $\quad$ The most accepted scenario (n, \%) $\quad 578 \quad 83.7$

- $\quad$ The least accepted scenario (n, \%) $\quad 133 \quad 25.4$

- Realistic influenza scenario (n, \%) $\quad 513 \quad 74.2$

- $\begin{array}{lll}\text { Realistic pertussis scenario (n, \%) } & 426\end{array}$

\begin{tabular}{lcc}
\hline $\begin{array}{l}\text { Willingness to accept incremental pain among } \\
\text { accepted scenarios } \\
\quad-\quad \text { Redness / swelling at the injection site (n, \%) }\end{array}$ & N=11,270 & \\
$\quad$ Minor pain during the injection (n, \%) & 112 & 46.0 \\
- $\quad$ Minor arm pain while three days (n, \%) & 2,182 & 9.9 \\
- One day in bed with fever (n, \%) & 2786 & 24.7 \\
\hline
\end{tabular}

SD: standard deviation

${ }^{a}$ Straight-liners are defined as those always refusing or accepting the hypothetical vaccines. 
Table 4. Preference weights for attributes of hypothetical vaccination acceptance (binary outcome) and willingness to accept increase in level of minor side effect (ordinal outcome) among 1214 hospital health care workers. France, June-September 2018.

\begin{tabular}{|c|c|c|c|c|c|}
\hline \multirow[b]{2}{*}{ Attributes } & \multirow[b]{2}{*}{ Levels } & \multicolumn{2}{|c|}{ Accept vaccination } & \multicolumn{2}{|c|}{$\begin{array}{l}\text { WTA increase in level } \\
\text { of minor side effect }\end{array}$} \\
\hline & & OR & $(95 \%-\mathrm{CI})$ & OR & $(95 \%-\mathrm{CI})$ \\
\hline \multirow[t]{4}{*}{ EPI } & normal & 1 & & 1 & \\
\hline & $\begin{array}{l}\text { cases } \\
\text { colleagues }\end{array}$ & 1.23 & $(1.06-1.42)$ & 1.15 & $(0.95-1.38)$ \\
\hline & cases patients & 1.33 & $(1.16-1.54)$ & 1.13 & $(0.96-1.34)$ \\
\hline & $\begin{array}{l}\text { authorities, high } \\
\text { risk }\end{array}$ & 1.76 & $(1.49-2.07)$ & 1.49 & $(1.22-1.80)$ \\
\hline \multirow[t]{4}{*}{ SAFETY } & $\begin{array}{l}\text { known, no side } \\
\text { effect }\end{array}$ & 1 & & 1 & \\
\hline & controversy & 0.04 & $(0.04-0.05)$ & 0.76 & $(0.64-0.90)$ \\
\hline & $\begin{array}{l}\text { known, neuro } \\
\text { effect }\end{array}$ & 0.05 & $(0.05-0.06)$ & 0.96 & $(0.82-1.12)$ \\
\hline & $\begin{array}{l}\text { recent, no side } \\
\text { effect }\end{array}$ & 0.30 & $(0.26-0.34)$ & 0.93 & $(0.81-1.07)$ \\
\hline \multirow[t]{4}{*}{ EFFECTIVENESS } & $30 \% 1 \mathrm{y}$ & 1 & & 1 & \\
\hline & $30 \% 3-5 y$ & 1.39 & $(1.20-1.60)$ & 1.00 & $(0.83-1.20)$ \\
\hline & $90 \% 1 \mathrm{y}$ & 1.73 & $(1.49-1.99)$ & 1.06 & $(0.90-1.26)$ \\
\hline & $90 \% 3-5 y$ & 2.22 & $(1.94-2.55)$ & 1.24 & $(1.05-1.47)$ \\
\hline \multirow[t]{5}{*}{ COVERAGE } & insufficient & 1 & & 1 & \\
\hline & VC $30 \%$ & 1.19 & $(1.03-1.37)$ & 0.82 & $(0.70-0.98)$ \\
\hline & VC $80 \%$ & 1.45 & $(1.26-1.67)$ & 0.93 & $(0.78-1.11)$ \\
\hline & Few colleagues & 1.04 & $(0.90-1.20)$ & 0.95 & $(0.80-1.13)$ \\
\hline & Most colleagues & 1.89 & $(1.63-2.19)$ & 1.00 & $(0.83-1.19)$ \\
\hline \multirow[t]{4}{*}{$\begin{array}{l}\text { INDIRECT } \\
\text { PROTECTION }\end{array}$} & individual only & 1 & & 1 & \\
\hline & disease control & 2.34 & $(1.98-2.77)$ & 1.20 & $(0.97-1.49)$ \\
\hline & family & 2.41 & $(2.04-2.84)$ & 1.43 & $(1.15-1.78)$ \\
\hline & patients & 2.08 & $(1.77-2.46)$ & 1.19 & $(0.96-1.46)$ \\
\hline \multirow[t]{4}{*}{ INCENTIVE } & no action & 1 & & 1 & \\
\hline & badge & 0.47 & $(0.41-0.54)$ & 0.88 & $(0.75-1.04)$ \\
\hline & certificate & $\mathbf{0 . 5 7}$ & $(0.50-0.65)$ & 0.97 & $(0.83-1.14)$ \\
\hline & hygiene & 0.79 & $(0.69-0.90)$ & 0.98 & $(0.83-1.15)$ \\
\hline \multirow[t]{2}{*}{ MANAGEMENT } & no message & 1 & & 1 & \\
\hline & message & 1.02 & $(0.91-1.14)$ & 0.94 & $(0.82-1.08)$ \\
\hline
\end{tabular}

OR: odds ratio. Results in bold are significant at the $5 \%$ level 95\%-CI: $95 \%$ confidence interval WTA: willingness-to-accept 
Table 5. Results of random intercept logit models of vaccination acceptance including interactions between attributes and individual characteristics. France, June-September 2018.

\begin{tabular}{|c|c|c|}
\hline Variables & $\begin{array}{c}\text { Estimates } \\
(\log \text { OR) }\end{array}$ & $95 \% \mathrm{CI}$ \\
\hline \multicolumn{3}{|l|}{ Individual characteristics } \\
\hline Age $(r e f=18-29)$ & ref & \\
\hline $30-49$ & -0.19 & {$[-0.77,0.39]$} \\
\hline $50-65+$ & 0.24 & {$[-0.39,0.87]$} \\
\hline \multicolumn{3}{|l|}{ Profession $(r e f=$ Nurse $)$} \\
\hline Doctor & $0.63 * *$ & {$[0.08,1.17]$} \\
\hline Nursing health manager & 0.04 & {$[-0.52,0.60]$} \\
\hline Other & -0.06 & {$[-0.68,0.56]$} \\
\hline \multicolumn{3}{|c|}{ Attitudes towards vaccination $($ ref $=$ Vaccinated $)$} \\
\hline Not vaccinated \& unfavorable & $-5.19 * * *$ & {$[-7.15,-3.22]$} \\
\hline Not vaccinated but favorable & $-2.83 * * *$ & {$[-3.46,-2.20]$} \\
\hline \multicolumn{3}{|c|}{ Attitudes towards influenza vaccination ( $r e f=$ Favorable $)$} \\
\hline Unfavorable & $-1.98 * * *$ & {$[-2.55,-1.42]$} \\
\hline \multicolumn{3}{|c|}{ Vaccine hesitancy ( $r e f=$ No hesitancy) } \\
\hline Low hesitancy & -0.02 & {$[-0.52,0.48]$} \\
\hline Medium hesitancy & $-1.27 * * *$ & {$[-2.11,-0.42]$} \\
\hline High hesitancy & $-1.18^{* * *}$ & {$[-1.71,-0.65]$} \\
\hline \multicolumn{3}{|l|}{ Trust in media $(r e f=N o)$} \\
\hline Yes & $0.67 * * *$ & {$[0.17,1.17]$} \\
\hline \multicolumn{3}{|c|}{ Use of alternative medicine ( $r e f=$ Do not use nor advise nor consult) } \\
\hline Uses, advises AND consults & -0.04 & {$[-0.68,0.60]$} \\
\hline Uses, advises OR consults & 0.16 & {$[-0.30,0.62]$} \\
\hline
\end{tabular}

\section{Attributes * Individual characteristics}

\section{EPI}

Normal

Cases colleagues ${ }^{\text {a }}$

ref

Cases patients ${ }^{\text {a }}$

$-0.08$

$[-0.32,0.15]$

Authorities, high risk ${ }^{\text {a }}$

$0.12 \quad[-0.12,0.36]$

$0.19 \quad[-0.09,0.48]$

Epi * Attitudes towards vaccination $($ ref $=$ Vaccinated $)$

Cases colleagues * Not vaccinated but favorable $\quad 0.41 * * \quad[0.09,0.74]$

Authorities, high risk * Not vaccinated but favorable

$0.49^{* *}$

$[0.11,0.87]$

\begin{tabular}{|c|c|c|}
\hline \multicolumn{3}{|l|}{ SAFETY } \\
\hline Known, no side effects & \multicolumn{2}{|c|}{ ref } \\
\hline Controversy $^{\mathrm{a}}$ & $-2.70 * * *$ & {$[-3.21,-2.19]$} \\
\hline Known, neuro effect ${ }^{a}$ & $-2.96 * * *$ & {$[-3.43,-2.48]$} \\
\hline Recent, no side effect ${ }^{a}$ & $-1.58 * * *$ & {$[-2.08,-1.09]$} \\
\hline \multicolumn{3}{|l|}{ Safety $*$ Age $(r e f=18-29 y)$} \\
\hline Controversy * 30-49 y & $-0.45 * *$ & {$[-0.89,-0.01]$} \\
\hline Recent, no side effect $* 50-65+y$ & $0.66 * * *$ & {$[0.21,1.11]$} \\
\hline \multicolumn{3}{|l|}{ Safety * Attitudes towards vaccination $(r e f=$ Vaccinated $)$} \\
\hline Known, neuro effect $*$ Not vaccinated \& unfavorable & $-1.48 * *$ & {$[-2.95,-0.00]$} \\
\hline Known, neuro effect $*$ Not vaccinated but favorable & $0.42 * *$ & {$[0.09,0.75]$} \\
\hline Recent, no side effect $*$ Not vaccinated $\&$ unfavorable & $-0.98 * *$ & {$[-1.87,-0.09]$} \\
\hline \multicolumn{3}{|l|}{ Safety $*$ Trust in media $(r e f=$ Do not trust $)$} \\
\hline Controversy $*$ Trust & $-0.82 * * *$ & {$[-1.25,-0.39]$} \\
\hline
\end{tabular}


Safety * Use of alternative medicine ( $r e f=$ Do not use nor advise nor consult $)$

Controversy * Use, advise AND consult $\quad-0.61 * *$

Known, neuro effect $*$ Use, advise AND consult

$[-1.09,-0.13]$

Known, neuro effect * Use, advise OR consult

$-0.48 * *$

$[-0.93,-0.03]$

EFFECTIVENESS

$30 \% 1 \mathrm{y}$

$30 \% 3-5 y^{a}$

$-0.40 * *$

$[-0.72,-0.09]$

$90 \% 1 y^{a}$

ref

$90 \% 3-5 y^{a}$

Effectiveness * Age $(r e f=18-29 y)$

$90 \% 3-5 y * 50-65+y$

Effectiveness * Attitudes towards vaccination $(r e f=$ Vaccinated $)$

90\% 3-5y * Not vaccinated but favorable

\section{COVERAGE}

Insufficient

VC $30 \%{ }^{\mathrm{a}}$

VC $80 \%{ }^{a}$

$0.47 * * * \quad[0.19,0.76]$

Few colleagues ${ }^{\text {a }}$

$0.31 * *$

$[0.04,0.58]$

Most colleagues ${ }^{\text {a }}$

0.16

$[-0.12,0.45]$

Coverage *Attitudes towards vaccination $(r e f=$ Vaccinated $)$

VC $30 \% *$ Not vaccinated but favorable

$0.65^{* * *}$

$[0.36,0.94]$

\section{INDIRECT PROTECTION}

Individual only

$-0.60 * * *$

$[-0.93,-0.28]$

Disease control $^{\text {a }}$

ref

Family $^{\text {a }}$

$0.96 * * *$

$[0.64,1.29]$

Patients ${ }^{\text {a }}$

$1.26 * * *$

$[0.94,1.58]$

Indirect protection * Attitudes towards vaccination ( $r e f=$ Vaccinated $)$

Patients * Not vaccinated but favorable

$1.01 * * *$

$[0.69,1.33]$

Indirect protection * Use of alternative medicine ( $r e f=$ Do not use

$-0.41^{* *}$

$[-0.77,-0.04]$ nor advise nor consult)

Family * Use, advise OR consult

$-0.40 * *$

$[-0.73,-0.07]$

\section{INCENTIVES}

No action

ref

Badge $^{a}$

$-1.09 * * * \quad[-1.36,-0.82]$

Certificate $^{a}$

$-0.71 * * * \quad[-0.99,-0.44]$

Hygiene $^{a}$

$-0.22 \quad[-0.49,0.05]$

Incentives * Vaccine hesitancy (ref $=$ No hesitancy)

Badge * Medium hesitancy

$0.62^{* *}$

$[0.03,1.21]$

Incentives * Attitudes towards vaccination $(r e f=$ Vaccinated $)$

Badge * Not vaccinated but favorable $\quad 0.36^{* *} \quad[0.05,0.68]$

Certificate * Not vaccinated but favorable

$0.26^{*} \quad[-0.04,0.57]$

\section{MANAGEMENT}

No message

ref

Message ${ }^{\text {a }}$

$0.13 \quad[-0.10,0.36]$

Management * Profession (ref $=$ Nurse)

Message * Nursing health manager

$0.41 * *$

$[0.07,0.74]$

Management * Vaccine Hesitancy (ref = No hesitancy)

Message * High hesitancy

$-0.35^{* * *} \quad[-0.61,-0.09]$

Note: only interaction effects (attributes*HCWs individual characteristics) significant at the $5 \%$ level are displayed. 
a Represents the impact of the attribute's level for the reference category / categories of the individual characteristics (e.g., age, gender, vaccination attitudes) used in the interaction model. Should not be interpreted as main effects.

Statistical significance: $* * *<1 \%, * *<5 \%, *<10 \%$

\section{Figures}

Figure 1. Example choice task

\section{Example scenario Q999}

Reminder: You participate in an information meeting that aims at promoting vaccination for health care professionals. The disease against which the vaccine protects is frequent, with low case fatality if no risk factor exists, but which may immobilize you during one week. It is easily transmitted through contact and aerosols. Vaccination is not mandatory but recommended by the Ministry of Health to your professional group. You can get vaccinated immediately and for free after this meeting.

- Few of your colleagues are vaccinated.

- The management asks the staff to get vaccinated, to protect patients and reduce days of work lost.

- Several of your patients have already been ill with this disease this month.

- The vaccine allows avoiding $\mathbf{3 0} \%$ of cases for a duration of $\mathbf{1}$ year.

- After vaccination, you can wear a badge "I am vaccinated".

- By getting vaccinated, you also protect your patients.

- The vaccine's safety profile is well known, it marginally increases the risk of developing a neurological disease.

\section{Question:}

Do you accept to get vaccinated now?

$$
\begin{array}{ll}
\text { 口 } & \text { Yes } \\
\text { D No }
\end{array}
$$

If yes, up to which minor side effect would you accept getting vaccinated?

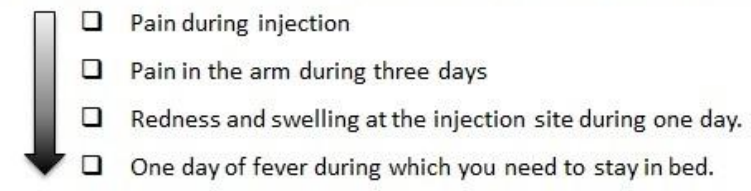

Note: Authors' translation from French into English. 
Figure 2. Importance of the seven attributes in the random effects logit model among 1214 hospital health care workers. France, June-September 2018

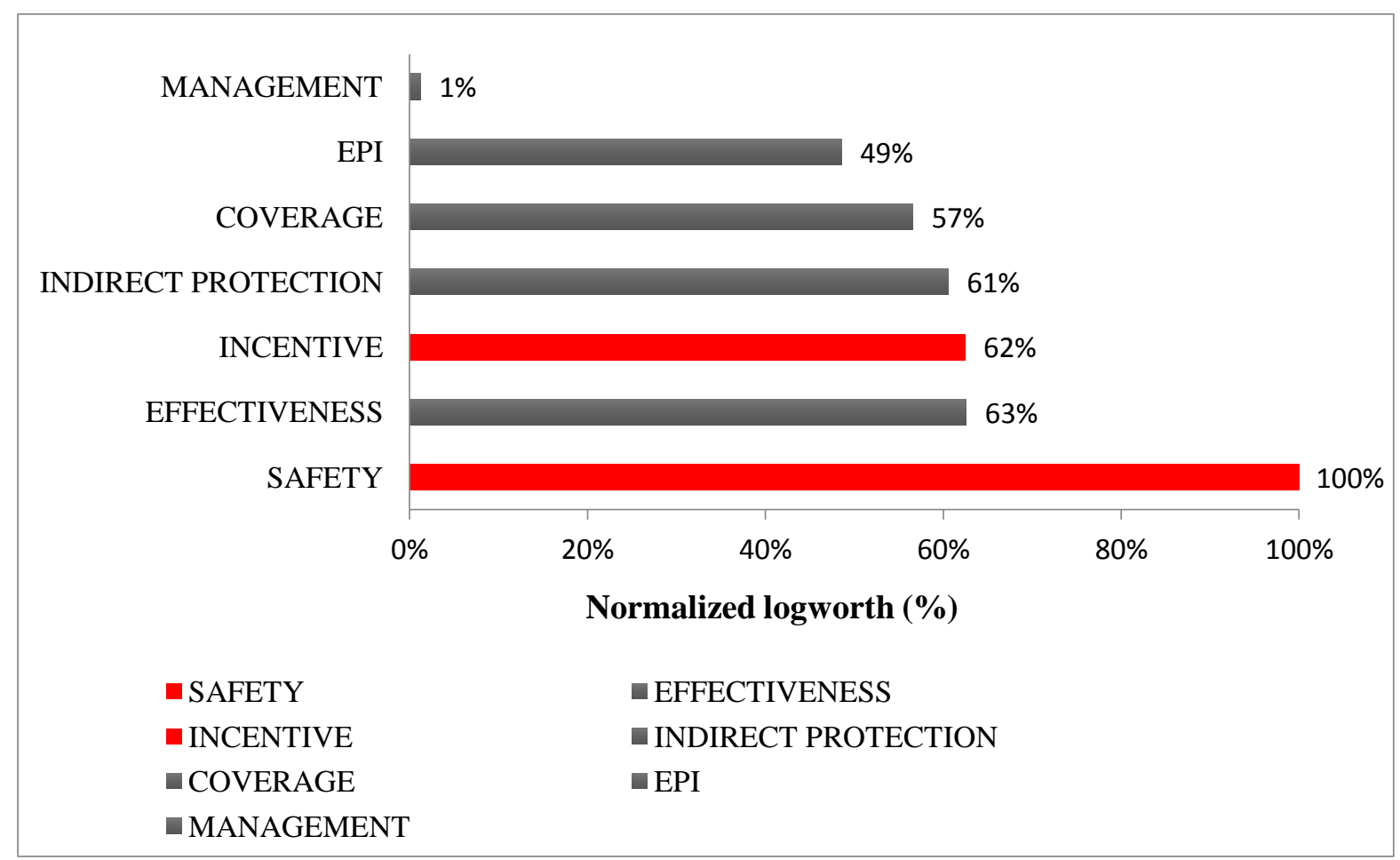

Note: The bar charts express the logworth statistic of each DCE attribute relatively to the logworth of the most important attribute: 'SAFETY' (normalized to 100\%).

Legend: Attributes highlighted in red color have a negative impact on stated vaccination acceptance. 
Supplementary materials (A, B, C) for the article "Quantifying preferences around vaccination against frequent, mild disease with risk for vulnerable persons: A discrete choice experiment among French hospital health care workers"

\section{Supplementary material A. Additional information on the experimental design}

Several constraints were added to the fractional design to avoid implausible combinations of attributes. In total, 6 constraints were imposed: the following combinations of attributes could note be selected in the final design (see the table A.1).

Table A1. Description of constraints added to the fractional design

\begin{tabular}{|c|l|}
\hline $\begin{array}{c}\text { Constraint } \\
\text { number }\end{array}$ & Implausible attributes' levels combinations \\
\hline \multirow{2}{*}{1} & The vaccine provides only individual protection. (individual only) \\
\cline { 2 - 3 } & $\begin{array}{l}\text { The management asks the HCW to get vaccinated to protect patients and } \\
\text { avoid absenteeism. (message) }\end{array}$ \\
\hline \multirow{2}{*}{2} & The vaccine provides only individual protection. (individual only) \\
\cline { 2 - 2 } 3 & Many of your patients have already been sick this year. (cases patients) \\
\hline \multirow{2}{*}{4} & The vaccine allows avoiding 30\% of cases over a 1-year period. (30\% 1y) \\
\cline { 2 - 3 } & $\begin{array}{l}\text { Vaccinating yourself allows participation in disease control. (disease control) } \\
\text { coming season. (authorities, high risk) }\end{array}$ \\
\cline { 2 - 3 } & $\begin{array}{l}\text { The management does not give any message regarding this vaccination. (no } \\
\text { message) }\end{array}$ \\
\hline \multirow{2}{*}{5} & The epidemic situation is normal with no worrying number of cases. (normal) \\
\cline { 2 - 3 } & $\begin{array}{l}\text { If the service vaccine coverage is low, hygiene rules will be reinforced. } \\
\text { (hygiene) }\end{array}$ \\
\hline \multirow{2}{*}{6} & Most of your coworkers are vaccinated. (most colleagues) \\
\cline { 2 - 2 } & Many of your colleagues have already been sick this year. (cases colleagues) \\
\hline
\end{tabular}

These constraints automatically generated some correlations between attributes, but these correlations were low as the final design was $90.5 \%$ D-efficient compared to the best possible orthogonal design. 
Figure A1. Most realistic scenario for influenza vaccination

\section{Reference scenario Influenza}

Reminder: You participate in an information meeting that aims at promoting vaccination for health care professionals. The disease against wich the vaccine protects if frequent, with low case fatality if no risk factor exists, but which may immobilize you during one week. It is easily transmitted through contact and aerosols. Vaccination is not mandatory but recommended by the Ministry of Health to your professional group. You can get vaccinated immediately and for free after this meeting.

- The vaccination coverage is insufficient among French HCWs

- The direction didn't send any specific message about this vaccination

- Several of your patients have already been ill with this disease this month

- The vaccine allows avoiding $30 \%$ of cases for the duration of 1 year

- There is no rewards nor restrictive measures announced

- By getting vaccinated, you participate to the control of the disease

- The vaccine's safety profile is well known, it marginally increases the risk of developing a neurological disease

\section{Question:}

- Do you accept to get vaccinated now?

$$
\begin{array}{ll}
\square & \text { Yes } \\
\square & \text { No }
\end{array}
$$

If yes, up to which minor side effect would you accept getting vaccinated?

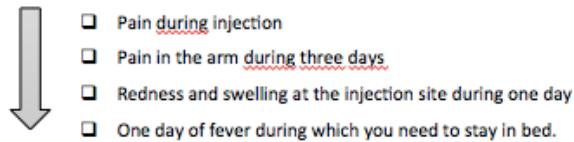

Figure A2. Most realistic scenario for pertussis vaccination.

\section{Reference scenario Pertussis}

Reminder: You participate in an information meeting that aims at promoting vaccination for health care professionals. The disease against wich the vaccine protects if frequent, with low case fatality if no risk factor exists, but which may immobilize you during one week. It is easily transmitted through contact an aerosols. Vaccination is not mandatory but recommended by the Ministry of Health to your professional group. You can get vaccinated immediately and for free after this meeting.

- $80 \%$ of French health care workers are vaccinated

- The direction didn't send any specific message about this vaccination

- Usual epidemiological situation

- The vaccine allows avoiding $\mathbf{3 0 \%}$ of cases for the duration of $\mathbf{3}$ to $\mathbf{5}$ years

- Display of a certificate if the vaccination coverage of your service exceeds $60 \%$

- By getting vaccinated, you also protect the vulnerable people in your family

- The vaccine is recent but no serious adverse effect is known

\section{Question:}

- Do you accept to get vaccinated now?

$$
\begin{array}{ll}
\square & \text { Yes } \\
\square & \text { No }
\end{array}
$$

If yes, up to which minor side effect would you accept getting vaccinated?

$$
\begin{aligned}
& \text { - Pain during injection } \\
& \text { a Pain in the arm during three days. } \\
& \text { a Redness and swelling at the injection site during one day } \\
& \text { a One day of fever during which you need to stay in bed. }
\end{aligned}
$$


Supplementary material B. Introduction to the choice tasks. Author's translations from French into English.

\section{Introduction}

- We will introduce you to 16 fictive vaccination scenarios. For each of them, we will ask you whether or not you would accept to be vaccinated in these conditions.

- Please try, as much as possible, to make your decision independently of yours answers to the others scenarios.

\section{Context}

You are attending an information meeting organized by the hygiene department - or the working health service of your hospital facility - in order to promote the interest of vaccination as a health car worker. Vaccination is not mandatory but recommended by the Ministry of Health to your professional group.

You can get vaccinated immediately and for free after this meeting.

The disease targeted by vaccination is described as:

- Frequent

- Rapidly evolving in few days

- Can be disabling the time of a week

- Can be easily transmitted through contact and aerosols even if there is no symptoms

- There is a low risk of fatality if there is no supplementary risk factor (e.g., being an infant, elderly or adult with chronic disease)

\section{Your decision for each scenario}

- Your first decision will be:

- 'Accept' or

- 'Don't accept' vaccination in these condition

- If you accept the vaccination, you must indicate for which maximum minor side effect

- Some minor side effects may occur (listed in order of increasing severity):

Pain during injection

Pain in the arm during three days

Redness and swelling at the injection site during one day

$\square$ One day of fever during which you need to stay in bed

These scenarios will vary according to various attributes:

The epidemic situation of the disease targeted by the vaccine. For instance, if some of your colleagues or patient have become ill or if the epidemic risk is estimated high by the public health authority.

\section{The vaccine safety:}

o The vaccine can be recent or well known

- The vaccine may or may not have known serious side effect listed 
- In some scenarios, the vaccination can be associated with a marginal increase in developing a disabling neurological disorder for life (usually affecting 35 out of every 100000 unvaccinated people, increasing to 39 out of every 100 000 people vaccinated).

- In some other scenarios, the media speak about a controversy about the vaccine safety. A small group of health care workers (including doctors) have alerted the public about the possibility of a serious side effect associated with this vaccine. However, the French health authority questions the relationship between these rare symptoms observed in some individuals and the vaccine.

$>$ The vaccine effectiveness (i.e., percentage of cases avoided by the vaccine for an adult in good health) and the duration of protection (e.g., 1 year, 3 to 5 years).

$>$ The vaccine coverage, determined by the prevalence of French coworkers being vaccinated, thus information on how the vaccine is accepted by your profession.

The possible indirect protection if you accept to be vaccinated: by getting vaccinated you can protect other people like your family or your patients.

The incentive to be vaccinated (e.g., badges or the hygiene rules will be reinforced).

The attitude of the management about this vaccination. For instance, the management can ask the HCW to get vaccinated to protect patients and avoid absenteeism. 
Supplementary material C. Additional results: sensitivity analyses and results of stratified models by HCW's individual characteristics.

Table C1. Sensitivity analysis: comparison of random intercept logit models of vaccination acceptance including / excluding straight-liners. France, June-September 2018

\begin{tabular}{|c|c|c|c|c|c|}
\hline \multirow[b]{2}{*}{ Attributes } & \multirow[b]{2}{*}{ Levels } & \multicolumn{2}{|r|}{$\begin{array}{l}\text { All respondents } \\
\qquad(\mathrm{N}=1214)\end{array}$} & \multicolumn{2}{|c|}{$\begin{array}{l}\text { Excluding straight- } \\
\text { liners }(N=859)\end{array}$} \\
\hline & & OR & $(95 \%-\mathrm{CI})$ & OR & $(95 \%-\mathrm{CI})$ \\
\hline \multirow[t]{4}{*}{ EPI } & normal & 1 & & 1 & \\
\hline & cases colleagues & 1.23 & $(1.06-1.42)$ & 1.24 & $(1.07-1.43)$ \\
\hline & cases patients & 1.33 & $(1.16-1.54)$ & 1.32 & $(1.14-1.53)$ \\
\hline & authorities: high risk & 1.76 & $(1.49-2.07)$ & 1.78 & $(1.51-2.10)$ \\
\hline \multirow[t]{4}{*}{ SAFETY } & known: no side effect & 1 & & 1 & \\
\hline & controversy & 0.04 & $(0.04-0.05)$ & 0.05 & $(0.04-0.05)$ \\
\hline & known: neuro effect & 0.05 & $(0.05-0.06)$ & 0.06 & $(0.05-0.07)$ \\
\hline & recent: no side effect & 0.30 & $(0.26-0.34)$ & 0.30 & $(0.26-0.35)$ \\
\hline \multirow[t]{4}{*}{ EFFECTIVENESS } & $30 \% 1 \mathrm{y}$ & 1 & & 1 & \\
\hline & $30 \% 3-5 y$ & 1.39 & $(1.20-1.60)$ & 1.38 & $(1.19-1.60)$ \\
\hline & $90 \% 1 \mathrm{y}$ & 1.73 & $(1.49-1.99)$ & 1.70 & $(1.47-1.96)$ \\
\hline & $90 \% 3-5 y$ & 2.22 & $(1.94-2.55)$ & 2.25 & $(1.95-2.58)$ \\
\hline \multirow[t]{5}{*}{ COVERAGE } & insufficient & 1 & & 1 & \\
\hline & VC $30 \%$ & 1.19 & $(1.03-1.37)$ & 1.18 & $(1.02-1.35)$ \\
\hline & VC $80 \%$ & 1.45 & $(1.26-1.67)$ & 1.47 & $(1.27-1.69)$ \\
\hline & few colleagues & 1.04 & $(0.90-1.20)$ & 1.01 & $(0.87-1.17)$ \\
\hline & most colleagues & 1.89 & $(1.63-2.19)$ & 1.87 & $(1.61-2.17)$ \\
\hline \multirow{4}{*}{$\begin{array}{l}\text { INDIRECT } \\
\text { PROTECTION }\end{array}$} & individual only & 1 & & 1 & \\
\hline & disease control & 2.34 & $(1.98-2.77)$ & 2.40 & $(2.02-2.84)$ \\
\hline & family & 2.41 & $(2.04-2.84)$ & 2.40 & $(2.04-2.84)$ \\
\hline & patients & 2.08 & $(1.77-2.46)$ & 2.11 & $(1.79-2.50)$ \\
\hline \multirow[t]{4}{*}{ INCENTIVE } & no action & 1 & & 1 & \\
\hline & badge & 0.47 & $(0.41-0.54)$ & 0.47 & $(0.41-0.54)$ \\
\hline & certificate & 0.57 & $(0.50-0.65)$ & 0.57 & $(0.50-0.65)$ \\
\hline & hygiene & 0.79 & $(0.69-0.90)$ & $\mathbf{0 . 7 8}$ & $(0.68-0.89)$ \\
\hline \multirow[t]{2}{*}{ MANAGEMENT } & no message & 1 & & 1 & \\
\hline & message & 1.02 & $(0.91-1.14)$ & 1.00 & $(0.89-1.13)$ \\
\hline
\end{tabular}

Straight-liners: respondents always refusing or accepting the hypothetical vaccines 
Table C2. Results of random intercept logit models of vaccination acceptance, stratified by professional groups. France, June-September 2018

\begin{tabular}{|c|c|c|c|c|c|c|c|}
\hline \multirow[b]{2}{*}{ Attributes: } & \multirow[b]{2}{*}{ Levels: } & \multicolumn{2}{|c|}{ Nurse $(n=880)$} & \multicolumn{2}{|c|}{ Doctor $(n=128)$} & \multicolumn{2}{|c|}{$\begin{array}{c}\text { Nursing health } \\
\text { manager }(n=110)\end{array}$} \\
\hline & & OR & $(95 \%-\mathrm{CI})$ & OR & $(95 \%-\mathrm{CI})$ & OR & $(95 \%-\mathrm{CI})$ \\
\hline \multirow[t]{4}{*}{ EPI } & normal & 1 & & 1 & & 1 & \\
\hline & cases colleagues & 1.30 & $(1.10-1.54)$ & 0.76 & $(0.46-1.27)$ & 1.21 & $(0.75-1.97)$ \\
\hline & cases patients & 1.32 & $(1.12-1.55)$ & 1.28 & $(0.76-2.16)$ & 1.74 & $(1.09-2.77)$ \\
\hline & $\begin{array}{l}\text { authorities: high } \\
\text { risk }\end{array}$ & 1.74 & $(1.44-2.10)$ & 1.56 & $(0.84-2.91)$ & 2.26 & $(1.32-3.87)$ \\
\hline \multirow[t]{4}{*}{ SAFETY } & $\begin{array}{l}\text { known: no side } \\
\text { effect }\end{array}$ & 1 & & 1 & & 1 & \\
\hline & controversy & 0.04 & $(0.04-0.05)$ & 0.04 & $(0.02-0.08)$ & 0.05 & $(0.03-0.08)$ \\
\hline & $\begin{array}{l}\text { known: neuro } \\
\text { effect }\end{array}$ & 0.05 & $(0.04-0.06)$ & 0.05 & $(0.03-0.09)$ & 0.08 & $(0.05-0.13)$ \\
\hline & $\begin{array}{l}\text { recent: no side } \\
\text { effect }\end{array}$ & 0.26 & $(0.22-0.31)$ & 0.32 & $(0.18-0.56)$ & 0.58 & $(0.37-0.93)$ \\
\hline \multirow[t]{4}{*}{ EFFECTIVENESS } & $30 \% 1 \mathrm{y}$ & 1 & & 1 & & 1 & \\
\hline & $30 \% 3-5 y$ & 1.36 & $(1.15-1.61)$ & 1.45 & $(0.87-2.43)$ & 2.07 & $(1.27-3.36)$ \\
\hline & $90 \% 1 \mathrm{y}$ & 1.83 & $(1.55-2.17)$ & 1.79 & $(1.06-3.04)$ & 1.68 & $(1.05-2.70)$ \\
\hline & $90 \% 3-5 y$ & 2.22 & $(1.89-2.60)$ & 2.53 & $(1.53-4.20)$ & 2.60 & $(1.64-4.12)$ \\
\hline \multirow[t]{5}{*}{ COVERAGE } & insufficient & 1 & & 1 & & 1 & \\
\hline & VC $30 \%$ & 1.21 & $(1.03-1.43)$ & 1.28 & $(0.78-2.11)$ & 1.03 & $(0.65-1.64)$ \\
\hline & VC $80 \%$ & 1.36 & $(1.15-1.59)$ & 2.12 & $(1.25-3.60)$ & 1.56 & $(0.97-2.50)$ \\
\hline & few colleagues & 1.00 & $(0.85-1.18)$ & 1.27 & $(0.74-2.16)$ & 0.98 & $(0.61-1.58)$ \\
\hline & most colleagues & 1.85 & $(1.56-2.19)$ & 2.04 & $(1.18-3.53)$ & 1.90 & $(1.15-3.14)$ \\
\hline \multirow[t]{4}{*}{$\begin{array}{l}\text { INDIRECT } \\
\text { PROTECTION }\end{array}$} & individual only & 1 & & 1 & & 1 & \\
\hline & disease control & 2.41 & $(1.98-2.93)$ & 2.08 & $(1.14-3.78)$ & 2.38 & $(1.36-4.17)$ \\
\hline & family & 2.53 & $(2.09-3.07)$ & 2.07 & $(1.18-3.62)$ & 2.44 & $(1.41-4.20)$ \\
\hline & patients & 2.17 & $(1.79-2.63)$ & 1.58 & $(0.88-2.81)$ & 1.94 & $(1.11-3.38)$ \\
\hline \multirow[t]{4}{*}{ INCENTIVE } & no action & 1 & & 1 & & 1 & \\
\hline & badge & 0.47 & $(0.40-0.55)$ & 0.37 & $(0.23-0.61)$ & 0.58 & $(0.37-0.91)$ \\
\hline & certificate & 0.57 & $(0.49-0.66)$ & 0.57 & $(0.34-0.95)$ & 0.55 & $(0.35-0.86)$ \\
\hline & hygiene & 0.79 & $(0.68-0.92)$ & 0.83 & $(0.50-1.36)$ & 0.82 & $(0.52-1.28)$ \\
\hline \multirow[t]{2}{*}{ MANAGEMENT } & no message & 1 & & 1 & & 1 & \\
\hline & message & 0.96 & $(0.84-1.09)$ & 1.52 & $(1.00-2.32)$ & 1.34 & $(0.91-1.96)$ \\
\hline
\end{tabular}

OR: odds ratio. Results in bold are significant at the $5 \%$ level 95\%-CI: $95 \%$ confidence interval 
Table C3. Results of random intercept logit models of vaccination acceptance, stratified by level of vaccine hesitancy. France, June-September 2018.

\begin{tabular}{|c|c|c|c|c|c|c|c|c|c|}
\hline \multirow[b]{2}{*}{ Attributes } & \multirow[b]{2}{*}{ Levels : } & \multicolumn{2}{|c|}{$\begin{array}{l}\text { No hesitancy } \\
\quad(n=535)\end{array}$} & \multicolumn{2}{|c|}{$\begin{array}{l}\text { Low hesitancy } \\
\qquad(n=292)\end{array}$} & \multicolumn{2}{|c|}{$\begin{array}{c}\text { Medium } \\
\text { hesitancy } \\
(n=71)\end{array}$} & \multicolumn{2}{|c|}{$\begin{array}{c}\text { Strong } \\
\text { hesitancy } \\
(\mathbf{n}=\mathbf{2 7 0})\end{array}$} \\
\hline & & OR & $(95 \%-\mathrm{CI})$ & OR & $(95 \%-\mathrm{CI})$ & OR & $(95 \%-\mathrm{CI})$ & OR & $(95 \%-\mathrm{CI})$ \\
\hline \multirow[t]{4}{*}{ EPI } & normal & 1 & & 1 & & 1 & & 1 & \\
\hline & $\begin{array}{l}\text { cases } \\
\text { colleagues }\end{array}$ & 1.20 & $(0.96-1.49)$ & 1.05 & $(0.77-1.42)$ & 1.04 & $(0.59-1.83)$ & 1.40 & $(1.02-1.92)$ \\
\hline & cases patients & 1.37 & $(1.10-1.71)$ & 1.29 & $(0.95-1.74)$ & 1.40 & $(0.80-2.44)$ & 1.25 & $(0.93-1.68)$ \\
\hline & $\begin{array}{l}\text { authorities: } \\
\text { high risk }\end{array}$ & 1.82 & $(1.40-2.35)$ & 1.59 & $(1.11-2.29)$ & 1.56 & $(0.84-2.91)$ & 1.68 & $(1.20-2.34)$ \\
\hline \multirow[t]{4}{*}{ SAFETY } & $\begin{array}{l}\text { known: no side } \\
\text { effect }\end{array}$ & 1 & & 1 & & 1 & & 1 & \\
\hline & controversy & 0.04 & $(0.03-0.06)$ & 0.04 & $(0.03-0.05)$ & $\mathbf{0 . 0 3}$ & $(0.02-0.06)$ & 0.05 & $(0.04-0.07)$ \\
\hline & $\begin{array}{l}\text { known: neuro } \\
\text { effect }\end{array}$ & 0.06 & $(0.05-0.07)$ & 0.04 & $(0.03-0.06)$ & $\mathbf{0 . 0 3}$ & $(0.02-0.06)$ & 0.07 & $(0.05-0.09)$ \\
\hline & $\begin{array}{l}\text { recent: no side } \\
\text { effect }\end{array}$ & 0.36 & $(0.29-0.44)$ & 0.27 & $(0.19-0.37)$ & 0.23 & $(0.13-0.39)$ & 0.27 & $(0.21-0.35)$ \\
\hline \multirow[t]{4}{*}{ EFFECTIVENESS } & $30 \% 1 \mathrm{y}$ & 1 & & 1 & & 1 & & 1 & \\
\hline & $30 \% 3-5 y$ & 1.39 & $(1.11-1.74)$ & 1.41 & $(1.03-1.93)$ & 1.38 & $(0.78-2.43)$ & 1.47 & $(1.08-2.01)$ \\
\hline & $90 \% 1 \mathrm{y}$ & 1.68 & $(1.35-2.10)$ & 1.70 & $(1.24-2.33)$ & 1.27 & $(0.72-2.22)$ & 2.04 & $(1.51-2.74)$ \\
\hline & $90 \% 3-5 y$ & 2.17 & $(1.75-2.68)$ & 2.19 & $(1.63-2.95)$ & 1.59 & $(0.94-2.67)$ & 2.56 & $(1.92-3.41)$ \\
\hline \multirow[t]{5}{*}{ COVERAGE } & insufficient & 1 & & 1 & & 1 & & 1 & \\
\hline & VC $30 \%$ & 1.19 & $(0.96-1.49)$ & 1.76 & $(1.29-2.39)$ & 1.00 & $(0.58-1.72)$ & 0.90 & $(0.67-1.20)$ \\
\hline & VC $80 \%$ & 1.57 & $(1.26-1.95)$ & 1.39 & $(1.03-1.88)$ & 1.15 & $(0.68-1.97)$ & 1.47 & $(1.10-1.97)$ \\
\hline & few colleagues & 1.07 & $(0.86-1.34)$ & 1.09 & $(0.80-1.48)$ & 0.76 & $(0.43-1.34)$ & 1.03 & $(0.76-1.39)$ \\
\hline & $\begin{array}{l}\text { most } \\
\text { colleagues }\end{array}$ & 1.92 & $(1.52-2.41)$ & 2.10 & $(1.53-2.90)$ & 1.61 & $(0.91-2.85)$ & 1.71 & $(1.26-2.32)$ \\
\hline \multirow[t]{4}{*}{$\begin{array}{l}\text { INDIRECT } \\
\text { PROTECTION }\end{array}$} & individual only & 1 & & 1 & & 1 & & 1 & \\
\hline & disease control & 2.41 & $(1.86-3.12)$ & 2.31 & $(1.63-3.30)$ & 1.92 & $(0.99-3.71)$ & 1.99 & $(1.39-2.85)$ \\
\hline & family & 2.53 & $(1.97-3.25)$ & 2.68 & $(1.90-3.78)$ & 1.73 & $(0.91-3.31)$ & 2.10 & $(1.47-3.00)$ \\
\hline & patients & 2.19 & $(1.70-2.82)$ & 2.32 & $(1.64-3.30)$ & 1.34 & $(0.71-2.55)$ & 1.79 & $(1.26-2.54)$ \\
\hline \multirow[t]{4}{*}{ INCENTIVES } & no action & 1 & & 1 & & 1 & & 1 & \\
\hline & badge & 0.44 & $(0.36-0.54)$ & 0.38 & $(0.28-0.51)$ & 0.80 & $(0.47-1.34)$ & 0.55 & $(0.41-0.73)$ \\
\hline & certificate & 0.56 & $(0.45-0.69)$ & 0.53 & $(0.39-0.71)$ & 0.88 & $(0.53-1.46)$ & 0.53 & $(0.41-0.70)$ \\
\hline & hygiene & $\mathbf{0 . 7 7}$ & $(0.62-0.94)$ & 0.70 & $(0.53-0.94)$ & 1.17 & $(0.70-1.95)$ & 0.92 & $(0.70-1.21)$ \\
\hline \multirow[t]{2}{*}{ MANAGEMENT } & no message & 1 & & 1 & & 1 & & 1 & \\
\hline & message & 1.11 & $(0.92-1.32)$ & 1.13 & $(0.88-1.44)$ & 1.41 & $(0.89-2.22)$ & 0.76 & $(0.59-0.96)$ \\
\hline
\end{tabular}

Results in bold are significant at the $5 \%$ level 
Table C4. Results of random intercept logit models of vaccination acceptance, stratified by influenza vaccination status during the 2017-18 season. France, June-September 2018.

\begin{tabular}{|c|c|c|c|c|c|}
\hline \multirow[b]{2}{*}{ Attributes } & \multirow[b]{2}{*}{ Levels : } & \multicolumn{2}{|c|}{ Vaccinated $(\mathrm{N}=628)$} & \multicolumn{2}{|c|}{ Not vaccinated $(\mathrm{N}=578)$} \\
\hline & & OR & $(95 \%-\mathrm{CI})$ & OR & $(95 \%-\mathrm{CI})$ \\
\hline \multirow[t]{4}{*}{ EPI } & normal & 1 & & 1 & \\
\hline & cases colleagues & 0.94 & $(0.74-1.17)$ & 1.40 & $(1.13-1.72)$ \\
\hline & cases patients & 1.12 & $(0.89-1.41)$ & 1.41 & $(1.16-1.72)$ \\
\hline & $\begin{array}{l}\text { authorities: high } \\
\text { risk }\end{array}$ & 1.25 & $(0.95-1.65)$ & 2.05 & $(1.64-2.56)$ \\
\hline \multirow[t]{4}{*}{ SAFETY } & $\begin{array}{l}\text { known: no side } \\
\text { effect }\end{array}$ & 1 & & 1 & \\
\hline & controversy & $\mathbf{0 . 0 3}$ & $(0.03-0.04)$ & 0.05 & $(0.04-0.06)$ \\
\hline & known: neuro effect & 0.04 & $(0.03-0.05)$ & 0.06 & $(0.05-0.08)$ \\
\hline & $\begin{array}{l}\text { recent: no side } \\
\text { effect }\end{array}$ & 0.27 & $(0.21-0.34)$ & 0.29 & $(0.25-0.35)$ \\
\hline \multirow[t]{4}{*}{ EFFECTIVENESS } & $30 \% 1 \mathrm{y}$ & 1 & & 1 & \\
\hline & $30 \% 3-5 y$ & 1.19 & $(0.95-1.48)$ & 1.46 & $(1.19-1.80)$ \\
\hline & $90 \% 1 \mathrm{y}$ & 1.54 & $(1.23-1.95)$ & 1.93 & $(1.58-2.35)$ \\
\hline & $90 \% 3-5 y$ & 1.59 & $(1.29-1.96)$ & 2.73 & $(2.25-3.32)$ \\
\hline \multirow[t]{5}{*}{ COVERAGE } & insufficient & 1 & & 1 & \\
\hline & VC $30 \%$ & 1.71 & $(1.37-2.15)$ & 0.90 & $(0.74-1.09)$ \\
\hline & VC $80 \%$ & 1.19 & $(0.97-1.47)$ & 1.62 & $(1.33-1.97)$ \\
\hline & Few colleagues & 1.15 & $(0.92-1.43)$ & 0.99 & $(0.81-1.21)$ \\
\hline & Most colleagues & 1.92 & $(1.52-2.42)$ & 1.84 & $(1.50-2.26)$ \\
\hline \multirow[t]{4}{*}{$\begin{array}{l}\text { INDIRECT } \\
\text { PROTECTION }\end{array}$} & individual only & 1 & & 1 & \\
\hline & disease control & 2.55 & $(1.99-3.27)$ & 2.16 & $(1.70-2.75)$ \\
\hline & family & 2.97 & $(2.34-3.79)$ & 2.08 & $(1.64-2.64)$ \\
\hline & patients & 2.81 & $(2.18-3.61)$ & 1.74 & $(1.38-2.20)$ \\
\hline \multirow[t]{4}{*}{ INCENTIVES } & no action & 1 & & 1 & \\
\hline & badge & 0.35 & $(0.28-0.43)$ & 0.54 & $(0.45-0.66)$ \\
\hline & certificate & 0.50 & $(0.40-0.62)$ & 0.63 & $(0.52-0.75)$ \\
\hline & hygiene & 0.81 & $(0.66-1.00)$ & 0.84 & $(0.70-1.01)$ \\
\hline \multirow[t]{2}{*}{ MANAGEMENT } & no message & 1 & & 1 & \\
\hline & message & 1.17 & $(0.98-1.40)$ & 0.88 & $(0.75-1.03)$ \\
\hline
\end{tabular}

Results in bold are significant at the $5 \%$ level 
Table C5. Results of random intercept logit models of vaccination acceptance, stratified by attitude towards vaccination in general. France, June-September 2018.

\begin{tabular}{|c|c|c|c|c|c|}
\hline \multirow[b]{2}{*}{ Attributes } & \multirow[b]{2}{*}{ Levels : } & \multicolumn{2}{|c|}{ Favorable $(n=1013)$} & \multicolumn{2}{|c|}{ Unfavorable $(n=201)$} \\
\hline & & OR & $(95 \%-\mathrm{CI})$ & OR & $(95 \%-\mathrm{CI})$ \\
\hline \multirow[t]{4}{*}{ EPI } & normal & 1 & & 1 & \\
\hline & cases colleagues & 1.23 & $(1.05-1.43)$ & 1.32 & $(0.85-2.03)$ \\
\hline & cases patients & 1.39 & $(1.19-1.62)$ & 1.06 & $(0.71-1.58)$ \\
\hline & authorities: high risk & 1.73 & $(1.45-2.07)$ & 1.87 & $(1.21-2.91)$ \\
\hline \multirow[t]{4}{*}{ SAFETY } & known: no side effect & 1 & & 1 & \\
\hline & controversy & 0.04 & $(0.04-0.05)$ & 0.04 & $(0.03-0.06)$ \\
\hline & known: neuro effect & 0.06 & $(0.05-0.07)$ & 0.04 & $(0.03-0.06)$ \\
\hline & recent: no side effect & 0.32 & $(0.27-0.37)$ & 0.23 & $(0.17-0.32)$ \\
\hline \multirow[t]{4}{*}{ EFFECTIVENESS } & $30 \% 1 \mathrm{y}$ & 1 & & 1 & \\
\hline & $30 \% 3-5 y$ & 1.39 & $(1.19-1.62)$ & 1.46 & $(0.97-2.20)$ \\
\hline & $90 \% 1 \mathrm{y}$ & 1.86 & $(1.58-2.17)$ & 1.23 & $(0.83-1.81)$ \\
\hline & $90 \% 3-5 y$ & 2.25 & $(1.94-2.62)$ & 1.94 & $(1.32-2.84)$ \\
\hline \multirow[t]{5}{*}{ COVERAGE } & insufficient & 1 & & 1 & \\
\hline & VC $30 \%$ & 1.26 & $(1.08-1.48)$ & 0.86 & $(0.58-1.27)$ \\
\hline & VC $80 \%$ & 1.45 & $(1.24-1.69)$ & 1.56 & $(1.05-2.30)$ \\
\hline & few colleagues & 1.11 & $(0.95-1.29)$ & 0.84 & $(0.56-1.26)$ \\
\hline & most colleagues & 1.96 & $(1.67-2.31)$ & 1.63 & $(1.09-2.45)$ \\
\hline \multirow[t]{4}{*}{$\begin{array}{l}\text { INDIRECT } \\
\text { PROTECTION }\end{array}$} & individual only & 1 & & 1 & \\
\hline & disease control & 2.34 & $(1.95-2.81)$ & 2.37 & $(1.44-3.90)$ \\
\hline & family & 2.53 & $(2.12-3.01)$ & 2.09 & $(1.27-3.43)$ \\
\hline & patients & 2.11 & $(1.76-2.52)$ & 1.96 & $(1.20-3.18)$ \\
\hline \multirow[t]{4}{*}{ INCENTIVE } & no action & 1 & & 1 & \\
\hline & badge & 0.47 & $(0.41-0.55)$ & 0.42 & $(0.28-0.62)$ \\
\hline & certificate & 0.58 & $(0.50-0.67)$ & 0.52 & $(0.36-0.74)$ \\
\hline & hygiene & 0.82 & $(0.71-0.95)$ & 0.71 & $(0.49-1.02)$ \\
\hline \multirow[t]{2}{*}{ MANAGEMENT } & no message & 1 & & 1 & \\
\hline & message & 1.05 & $(0.93-1.19)$ & 0.85 & $(0.61-1.17)$ \\
\hline
\end{tabular}

Results in bold are significant at the $5 \%$ level 
Table C6. Results of random intercept logit models of vaccination acceptance, stratified by trust in vaccine information from media. France, June-September 2018

\begin{tabular}{llrrrr}
\hline \multirow{2}{*}{ Attributes } & & \multicolumn{2}{c}{ No trust (n=1008) } & & Trust (n=206) \\
\hline EPI & Levels : & OR & $(95 \%-C I)$ & OR & $(95 \%-C I)$ \\
& normal & 1 & & 1 & \\
& cases colleagues & $\mathbf{1 . 2 9}$ & $(1.10-1.52)$ & 0.98 & $(0.69-1.40)$ \\
& cases patients & $\mathbf{1 . 3 7}$ & $(1.17-1.60)$ & 1.19 & $(0.84-1.69)$ \\
& authorities: high risk & $\mathbf{1 . 7 1}$ & $(1.43-2.04)$ & $\mathbf{2 . 0 5}$ & $(1.37-3.06)$ \\
\hline SAFETY & known: no side effect & 1 & & 1 & \\
& controversy & $\mathbf{0 . 0 5}$ & $(0.04-0.06)$ & $\mathbf{0 . 0 2}$ & $(0.01-0.03)$ \\
& known: neuro effect & $\mathbf{0 . 0 6}$ & $(0.05-0.07)$ & $\mathbf{0 . 0 4}$ & $(0.03-0.06)$ \\
& recent: no side effect & $\mathbf{0 . 3 1}$ & $(0.26-0.36)$ & $\mathbf{0 . 2 5}$ & $(0.18-0.36)$ \\
\hline EFFECTIVENESS & 30\% 1y & 1 & & 1 & \\
& 30\% 3-5y & $\mathbf{1 . 4 1}$ & $(1.20-1.66)$ & 1.29 & $(0.90-1.84)$ \\
& $90 \%$ 1y & $\mathbf{1 . 7 8}$ & $(1.52-2.09)$ & $\mathbf{1 . 5 1}$ & $(1.06-2.17)$ \\
& 90\% 3-5y & $\mathbf{2 . 2 1}$ & $(1.90-2.57)$ & $\mathbf{2 . 3 4}$ & $(1.66-3.28)$ \\
\hline COVERAGE & insufficient & 1 & & 1 & \\
& VC 30\% & 1.14 & $(0.98-1.34)$ & 1.38 & $(0.98-1.95)$ \\
& VC 80\% & $\mathbf{1 . 3 9}$ & $(1.20-1.63)$ & $\mathbf{1 . 7 8}$ & $(1.26-2.52)$ \\
& few colleagues & 1.01 & $(0.86-1.18)$ & 1.18 & $(0.83-1.70)$ \\
& most colleagues & $\mathbf{1 . 8 1}$ & $(1.53-2.13)$ & $\mathbf{2 . 4 0}$ & $(1.67-3.47)$ \\
\hline INDIRECT & individual only & 1 & & 1 & \\
PROTECTION & disease control & $\mathbf{2 . 3 5}$ & $(1.95-2.83)$ & $\mathbf{2 . 3 5}$ & $(1.55-3.55)$ \\
& family & $\mathbf{2 . 4 2}$ & $(2.02-2.90)$ & $\mathbf{2 . 4 3}$ & $(1.61-3.66)$ \\
& patients & $\mathbf{2 . 0 9}$ & $(1.74-2.51)$ & $\mathbf{2 . 1 1}$ & $(1.40-3.18)$ \\
\hline MANAGEMENT & no action & 1 & & 1 & \\
& no message & & & & \\
& message & $\mathbf{0 . 4 5}$ & $(0.39-0.52)$ & $\mathbf{0 . 5 7}$ & $(0.41-0.80)$ \\
& badge & $\mathbf{0 . 5 5}$ & $(0.48-0.64)$ & $\mathbf{0 . 6 5}$ & $(0.47-0.89)$ \\
& hertificate & $\mathbf{0 . 7 9}$ & $(0.68-0.91)$ & 0.80 & $(0.58-1.11)$ \\
\hline & 1.03 & $(0.90-1.17)$ & 0.98 & $(0.73-1.31)$ \\
\hline
\end{tabular}

Results in bold are significant at the 5\% level 
Table C7. Results of random intercept logit models of vaccination acceptance, stratified by use of alternative medicine. France, June-September 2018.

\begin{tabular}{|c|c|c|c|c|c|c|c|}
\hline \multirow[b]{2}{*}{ Attributes } & \multirow[b]{2}{*}{ Levels : } & \multicolumn{2}{|c|}{$\begin{array}{l}\text { Uses*, advises** and } \\
\text { consults } \$(n=178)\end{array}$} & \multicolumn{2}{|c|}{$\begin{array}{l}\text { Uses, advises or } \\
\text { consults }(n=559)\end{array}$} & \multicolumn{2}{|c|}{$\begin{array}{r}\text { Does not use, nor } \\
\text { advise nor consult } \\
(\mathrm{n}=421)\end{array}$} \\
\hline & & OR & $(95 \%-\mathrm{CI})$ & OR & $(95 \%-\mathrm{CI})$ & OR & $(95 \%-\mathrm{CI})$ \\
\hline \multirow[t]{4}{*}{ EPI } & normal & 1 & & 1 & & 1 & \\
\hline & $\begin{array}{l}\text { cases } \\
\text { colleagues }\end{array}$ & 1.34 & $(0.89-1.99)$ & 1.23 & $(1.00-1.52)$ & 1.19 & $(0.92-1.54)$ \\
\hline & cases patients & 1.27 & $(0.86-1.87)$ & 1.37 & $(1.12-1.68)$ & 1.33 & $(1.04-1.71)$ \\
\hline & $\begin{array}{l}\text { authorities: } \\
\text { high risk }\end{array}$ & 1.33 & $(0.86-2.06)$ & 2.08 & $(1.64-2.64)$ & 1.50 & $(1.13-2.00)$ \\
\hline \multirow[t]{4}{*}{ SAFETY } & $\begin{array}{l}\text { known: no } \\
\text { side effect }\end{array}$ & 1 & & 1 & & 1 & \\
\hline & controversy & 0.03 & $(0.02-0.04)$ & 0.04 & $(0.03-0.05)$ & 0.05 & $(0.04-0.07)$ \\
\hline & $\begin{array}{l}\text { known: neuro } \\
\text { effect }\end{array}$ & 0.04 & $(0.03-0.06)$ & 0.05 & $(0.04-0.06)$ & 0.07 & $(0.06-0.09)$ \\
\hline & $\begin{array}{l}\text { recent: no side } \\
\text { effect }\end{array}$ & 0.26 & $(0.18-0.37)$ & 0.27 & $(0.22-0.33)$ & 0.37 & $(0.29-0.48)$ \\
\hline \multirow[t]{4}{*}{ EFFECTIVENESS } & $30 \% 1 \mathrm{y}$ & 1 & & 1 & & 1 & \\
\hline & $30 \% 3-5 y$ & 1.43 & $(0.96-2.13)$ & 1.33 & $(1.08-1.64)$ & 1.36 & $(1.05-1.76)$ \\
\hline & $90 \% 1 \mathrm{y}$ & 1.67 & $(1.12-2.50)$ & 1.66 & $(1.35-2.03)$ & 1.57 & $(1.22-2.03)$ \\
\hline & $90 \% 3-5 y$ & 2.10 & $(1.45-3.04)$ & 2.20 & $(1.81-2.68)$ & 2.09 & $(1.64-2.67)$ \\
\hline \multirow[t]{5}{*}{ COVERAGE } & insufficient & 1 & & 1 & & 1 & \\
\hline & VC $30 \%$ & 0.86 & $(0.59-1.27)$ & 1.24 & $(1.01-1.51)$ & 1.29 & $(1.00-1.65)$ \\
\hline & VC $80 \%$ & 1.25 & $(0.86-1.81)$ & 1.55 & $(1.26-1.89)$ & 1.43 & $(1.12-1.83)$ \\
\hline & few colleagues & 0.89 & $(0.60-1.33)$ & 1.06 & $(0.86-1.31)$ & 0.97 & $(0.76-1.25)$ \\
\hline & $\begin{array}{l}\text { most } \\
\text { colleagues }\end{array}$ & 1.49 & $(1.00-2.24)$ & 1.87 & $(1.52-2.32)$ & 1.90 & $(1.46-2.47)$ \\
\hline \multirow[t]{4}{*}{$\begin{array}{l}\text { INDIRECT } \\
\text { PROTECTION }\end{array}$} & $\begin{array}{l}\text { Individual } \\
\text { only }\end{array}$ & 1 & & 1 & & 1 & \\
\hline & disease control & 3.33 & $(2.09-5.32)$ & 1.97 & $(1.55-2.51)$ & 2.65 & $(1.97-3.56)$ \\
\hline & family & 3.09 & $(1.95-4.90)$ & 1.88 & $(1.48-2.38)$ & 3.07 & $(2.30-4.10)$ \\
\hline & patients & 2.80 & $(1.77-4.43)$ & 1.80 & $(1.42-2.28)$ & 2.24 & $(1.68-3.00)$ \\
\hline \multirow[t]{4}{*}{ INCENTIVE } & no action & 1 & & 1 & & 1 & \\
\hline & badge & 0.55 & $(0.38-0.80)$ & 0.50 & $(0.41-0.61)$ & 0.38 & $(0.30-0.48)$ \\
\hline & certificate & 0.70 & $(0.49-0.99)$ & 0.60 & $(0.50-0.73)$ & 0.47 & $(0.37-0.59)$ \\
\hline & hygiene & 0.90 & $(0.63-1.29)$ & 0.80 & $(0.66-0.97)$ & 0.71 & $(0.56-0.90)$ \\
\hline \multirow[t]{2}{*}{ MANAGEMENT } & no message & 1 & & 1 & & 1 & \\
\hline & message & 1.11 & $(0.81-1.52)$ & 1.03 & $(0.88-1.22)$ & 1.01 & $(0.82-1.24)$ \\
\hline \multicolumn{8}{|c|}{$\begin{array}{l}\text { * If answered 'yes' to the question: "Do you use homeopathic products as an alternative to influenza vaccine"? } \\
\text { ** If answered 'yes' to the question: "Do you recommend one or more of these alternative medicines to the } \\
\text { patients with whom you are in contact?" } \\
\text { § If answered 'yes' to the question: "Do you consult specialists of alternative medicine (e.g., acupuncturist, } \\
\text { homeopath, relaxation therapist, etc.)"? }\end{array}$} \\
\hline
\end{tabular}


Table C8. Results of random intercept logit models of vaccination acceptance, stratified by attitude towards influenza vaccination. France, June-September 2018.

\begin{tabular}{|c|c|c|c|c|c|}
\hline \multirow[b]{2}{*}{ Attributes } & \multirow[b]{2}{*}{ Levels } & \multicolumn{2}{|c|}{$\begin{array}{l}\text { Unfavorable to influenza } \\
\text { vaccination }(\mathrm{N}=\mathbf{2 0 0})\end{array}$} & \multicolumn{2}{|c|}{$\begin{array}{l}\text { Favorable to influenza } \\
\text { vaccination }(\mathrm{N}=1014)\end{array}$} \\
\hline & & OR & $(95 \%-\mathrm{CI})$ & OR & $(95 \%-\mathrm{CI})$ \\
\hline \multirow[t]{4}{*}{ EPI } & normal & 1 & & 1 & \\
\hline & cases colleagues & 1.39 & $(0.95-2.03)$ & 1.18 & $(1.00-1.38)$ \\
\hline & cases patients & 1.46 & $(1.02-2.09)$ & 1.32 & $(1.12-1.54)$ \\
\hline & authorities: high risk & 2.23 & $(1.49-3.33)$ & 1.66 & $(1.38-1.99)$ \\
\hline \multirow[t]{4}{*}{ SAFETY } & known: no side effect & 1 & & 1 & \\
\hline & controversy & 0.06 & $(0.04-0.08)$ & 0.04 & $(0.03-0.05)$ \\
\hline & known: neuro effect & 0.09 & $(0.06-0.13)$ & 0.05 & $(0.04-0.06)$ \\
\hline & recent: no side effect & 0.35 & $(0.26-0.48)$ & 0.28 & $(0.24-0.33)$ \\
\hline \multirow[t]{4}{*}{ EFFECTIVENESS } & $30 \% 1 \mathrm{y}$ & 1 & & 1 & \\
\hline & $30 \% 3-5 y$ & 1.44 & $(0.99-2.12)$ & 1.36 & $(1.16-1.60)$ \\
\hline & $90 \% 1 \mathrm{y}$ & 2.78 & $(1.95-3.97)$ & 1.13 & $(1.34-1.85)$ \\
\hline & $90 \% 3-5 y$ & 3.93 & $(2.77-5.60)$ & 1.15 & $(1.71-2.31)$ \\
\hline \multirow[t]{5}{*}{ COVERAGE } & insufficient & 1 & & 1 & \\
\hline & VC $30 \%$ & 0.90 & $(0.63-1.29)$ & 1.25 & $(1.07-1.46)$ \\
\hline & VC $80 \%$ & 1.48 & $(1.04-2.11)$ & 1.42 & $(1.22-1.66)$ \\
\hline & few colleagues & 1.15 & $(0.80-1.65)$ & 1.02 & $(0.87-1.19)$ \\
\hline & most colleagues & 1.70 & $(1.18-2.44)$ & 1.94 & $(1.64-2.28)$ \\
\hline \multirow[t]{4}{*}{$\begin{array}{l}\text { INDIRECT } \\
\text { PROTECTION }\end{array}$} & themself only & 1 & & 1 & \\
\hline & disease control & 1.74 & $(1.13-2.70)$ & 2.43 & $(2.01-2.92)$ \\
\hline & family & 2.04 & $(1.33-3.14)$ & 2.50 & $(2.09-2.99)$ \\
\hline & patients & 1.87 & $(1.3-2.83)$ & 2.13 & $(1.77-2.55)$ \\
\hline \multirow[t]{4}{*}{ INCENTIVES } & no action & 1 & & 1 & \\
\hline & badge & 0.59 & $(0.41-0.84)$ & 0.45 & $(0.39-0.52)$ \\
\hline & certificate & 0.68 & $(0.49-0.93)$ & 0.56 & $(0.48-0.65)$ \\
\hline & hygiene & 0.91 & $(0.65-1.27)$ & 0.79 & $(0.68-0.91)$ \\
\hline \multirow[t]{2}{*}{ MANAGEMENT } & no message & 1 & & 1 & \\
\hline & message & 0.79 & $(0.59-1.06)$ & 1.18 & $(1.00-1.38)$ \\
\hline
\end{tabular}

Results in bold are significant at the 5\% level 
Table C9. Results of random intercept logit models of vaccination acceptance, stratified by influenza vaccination 2017-18 and attitude towards vaccines in general. France, June-September 2018

\begin{tabular}{|c|c|c|c|c|c|c|}
\hline & \multicolumn{2}{|c|}{$\begin{array}{l}\text { Not vaccinated and vaccine- } \\
\text { unfavorable }(n=76)\end{array}$} & \multicolumn{2}{|c|}{$\begin{array}{l}\text { Not vaccinated but } \\
\text { vaccine-favorable } \\
(n=502)\end{array}$} & \multicolumn{2}{|c|}{ Vaccinated $(n=628)$} \\
\hline & OR & $(95 \%-\mathrm{CI})$ & OR & $(95 \%-\mathrm{CI})$ & OR & $(95 \%-\mathrm{CI})$ \\
\hline \multicolumn{7}{|l|}{ EPI } \\
\hline normal & 1 & & 1 & & 1 & \\
\hline cases colleagues & 4.13 & $(0.73-23.51)$ & 1.34 & $(1.09-1.66)$ & 0.94 & $(0.74-1.17)$ \\
\hline cases patients & 4.67 & (1.04-20.99) & 1.34 & $(1.10-1.64)$ & 1.12 & $(0.89-1.41)$ \\
\hline authorities: high risk & 4.93 & $(0.95-25.52)$ & 1.97 & $(1.56-2.47)$ & 1.25 & $(0.95-1.65)$ \\
\hline \multicolumn{7}{|l|}{ SAFETY } \\
\hline \multirow{2}{*}{$\begin{array}{r}\text { known: no side effect } \\
\text { controversy }\end{array}$} & 1 & & 1 & & 1 & \\
\hline & 0.01 & $(0.00-0.05)$ & 0.05 & $(0.04-0.06)$ & $\mathbf{0 . 0 3}$ & $(0.03-0.04)$ \\
\hline known: neuro effect & 0.01 & $(0.00-0.05)$ & 0.07 & $(0.06-0.08)$ & 0.04 & $(0.03-0.05)$ \\
\hline recent: no side effect & 0.12 & $(0.05-0.26)$ & 0.31 & $(0.26-0.38)$ & 0.27 & $(0.21-0.34)$ \\
\hline \multicolumn{7}{|l|}{ EFFECTIVENESS } \\
\hline $30 \% 1 \mathrm{y}$ & 1 & & 1 & & 1 & \\
\hline $30 \% 3-5 y$ & 1.42 & $(0.36-5.57)$ & 1.46 & $(1.18-1.81)$ & 1.19 & $(0.95-1.48)$ \\
\hline $90 \% 1 \mathrm{y}$ & 1.62 & $(0.59-4.51)$ & 1.96 & $(1.60-2.40)$ & 1.54 & $(1.23-1.95)$ \\
\hline $90 \% 3-5 y$ & 0.75 & $(0.16-3.47)$ & 2.84 & $(2.33-3.47)$ & 1.59 & $(1.29-1.96)$ \\
\hline \multicolumn{7}{|l|}{ COVERAGE } \\
\hline insufficient & 1 & & 1 & & 1 & \\
\hline VC $30 \%$ & 1.02 & $(0.28-3.72)$ & 0.91 & $(0.74-1.11)$ & 1.71 & $(1.37-2.15)$ \\
\hline VC $80 \%$ & 3.68 & $(0.87-15.60)$ & 1.63 & $(1.34-2.00)$ & 1.19 & $(0.97-1.47)$ \\
\hline few colleagues & 1.01 & $(0.25-4.06)$ & 1.01 & $(0.82-1.24)$ & 1.15 & $(0.92-1.43)$ \\
\hline most colleagues & 3.42 & $(0.77-15.20)$ & 1.87 & $(1.52-2.30)$ & 1.92 & $(1.52-2.42)$ \\
\hline \multicolumn{7}{|l|}{ INDIRECT PROTECTION } \\
\hline \multirow{3}{*}{$\begin{array}{r}\text { individual only } \\
\text { disease control } \\
\text { family }\end{array}$} & 1 & & 1 & & 1 & \\
\hline & 2.13 & $(0.39-11.72)$ & 2.22 & $(1.73-2.83)$ & 2.55 & $(1.99-3.27)$ \\
\hline & 0.83 & $(0.12-5.59)$ & 2.17 & $(1.70-2.76)$ & 2.97 & $(2.34-3.79)$ \\
\hline patients & 0.90 & $(0.17-4.74)$ & 1.84 & $(1.45-2.34)$ & 2.81 & $(2.18-3.61)$ \\
\hline \multicolumn{7}{|l|}{ INCENTIVE } \\
\hline no action & 1 & & 1 & & 1 & \\
\hline badge & 0.27 & $(0.07-1.08)$ & 0.54 & $(0.44-0.66)$ & 0.35 & $(0.28-0.43)$ \\
\hline certificate & 0.27 & $(0.07-1.10)$ & 0.61 & $(0.51-0.74)$ & 0.50 & $(0.40-0.62)$ \\
\hline hygiene & 0.37 & $(0.09-1.45)$ & 0.83 & $(0.69-1.01)$ & 0.81 & $(0.66-1.00)$ \\
\hline MANAGEMENT & & & & & & \\
\hline no message & 1 & & 1 & & 1 & \\
\hline message & 0.56 & $(0.18-1.79)$ & 0.89 & $(0.75-1.04)$ & 1.17 & $(0.98-1.40)$ \\
\hline
\end{tabular}

Results in bold are significant at the $5 \%$ level 
Figure C1. Preference weights (odds ratio) and 95\% confidence intervals for attributes of vaccination acceptance, among 1214 hospital health care

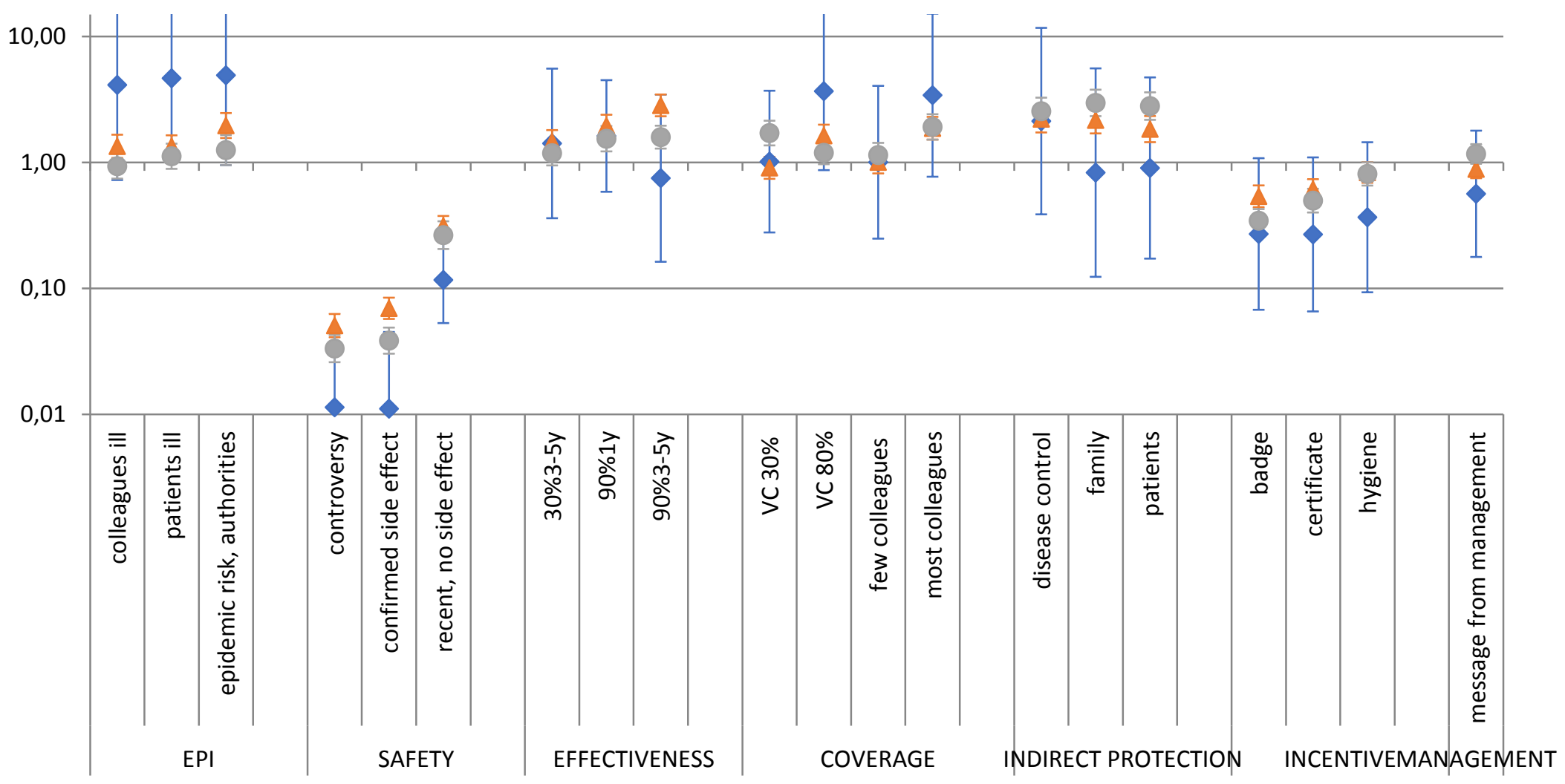

workers, stratified by

influenza

vaccination 2017-18 and attitude towards vaccines in general. France, JuneSeptember 2018

$\diamond$ not vaccinated and unfavorable $\quad \Delta$ not vaccinated, but favorable vaccinated

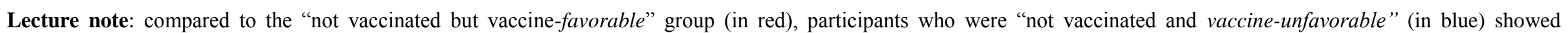

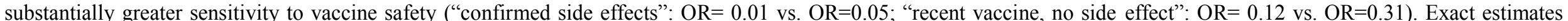
(OR) underpinning this Figure are displayed in supplementary Table C9. 